\title{
Progress in the overall understanding of typhoid fever: implications for vaccine development
}

\author{
Peter J O’Reilly, Dikshya Pant, Mila Shakya, Buddha Basnyat \& Andrew J \\ Pollard
}

To cite this article: Peter J O'Reilly, Dikshya Pant, Mila Shakya, Buddha Basnyat \& Andrew J Pollard (2020): Progress in the overall understanding of typhoid fever: implications for vaccine development, Expert Review of Vaccines, DOI: 10.1080/14760584.2020.1750375

To link to this article: https://doi.org/10.1080/14760584.2020.1750375

冓盟

Accepted author version posted online: 02 Apr 2020.

Submit your article to this journal ๒

山 Article views: 1

Q View related articles ¿

View Crossmark data 
Publisher: Taylor \& Francis \& Informa UK Limited, trading as Taylor \& Francis Group

Journal: Expert Review of Vaccines

DOI: $10.1080 / 14760584.2020 .1750375$

\section{Progress in the overall understanding of typhoid fever: implications for vaccine development}

Peter J O’Reilly ${ }^{1}$, Dikshya Pant ${ }^{2}$, Mila Shakya ${ }^{3}$, Buddha Basnyat ${ }^{3}$, Andrew J Pollard $^{1}$

${ }^{1}$ Oxford Vaccine Group, Department of Pediatrics, University of Oxford and the NIHR Oxford Biomedical Research Centre, Oxford, UK

${ }^{2}$ Patan Academy of Health Sciences, Patan Hospital, Kathmandu, Nepal

${ }^{3}$ Oxford University Clinical Research Unit, Patan Academy of Health Sciences, Kathmandu, Nepal

Corresponding Author:

Peter O'Reilly, Oxford Vaccine Group, Centre for Clinical Vaccinology \& Tropical Medicine, The Churchill Hospital, Old Road, Oxford, OX3 7LE

peter.oreilly@paediatrics.ox.ac.uk

Funding: This paper was funded by the Bill \& Melinda Gates Foundation and the NIHR Oxford Biomedical Research Centre.

Declaration of Interest: A J Pollard is Chair of UK Department of Health and Social Care's (DHSC) Joint Committee on Vaccination \& Immunisation (JCVI) \& the European Medicine Agency (EMA) scientific advisory group on vaccines, and is a member of the WHO's Strategic Advisory Group of Experts. The views expressed in this article do not necessarily represent the views of DHSC, JCVI or WHO. The authors have no other relevant affiliations or financial involvement with any organization or entity with a financial interest in or financial conflict with the subject matter or materials discussed in the manuscript apart from those disclosed.

Reviewer Disclosures: Peer reviewers on this manuscript have no relevant financial or other relationships to disclose.

Author Contributions: P O'Reilly, M Shakya and D Pant drafted the manuscript which was edited by A J Pollard and B Basnyat. All authors reviewed and approved the final draft. 


\section{ABSTRACT}

Introduction: Typhoid fever continues to have a substantial impact on human health, especially in Asia and sub-Saharan Africa. Access to safe water, and adequate sanitation and hygiene remain the cornerstone of prevention, but these are not widely available in many impoverished settings. The emergence of antibiotic resistance affects typhoid treatment and adds urgency to typhoid control efforts. Vaccines provide opportunities to prevent and control typhoid fever in endemic settings.

Areas covered: Literature search was performed looking for evidence concerning the global burden of typhoid and strategies for prevention and treatment of typhoid fever. Cost of illness, available typhoid and paratyphoid vaccines and cost effectiveness were also reviewed. The objective was to provide a critical overview of typhoid fever, in order to assess the current understanding and potential future directions for typhoid treatment and control.

Expert Opinion: Our understanding of typhoid burden and methods of prevention has grown over recent years. However, typhoid fever still has a significant impact on health in low and middle income countries. Introduction of typhoid conjugate vaccines to the immunization schedule is expected to make a major contribution to control of typhoid fever in endemic countries, although vaccination alone is unlikely to eliminate the disease.

\section{Keywords}

- Typhoid

- Paratyphoid

- Vaccination

- Vaccine development

- Enteric fever

- Typhoid conjugate vaccine 


\section{Article Highlights}

- Globally, overall rates of typhoid fever are reported to be falling, however there are between 11.9 - 26.9 million cases of typhoid fever each year with $129,000-$ 135,900 deaths.

- $\quad$ Several countries across Asia and sub-Saharan Africa have high reported incidences of typhoid fever. The Global Burden of Disease Study 2017 reported that the South Asia super-region had the highest incidence of typhoid fever globally.

- $\quad$ Provision of clean drinking water, adequate sanitation and safe food handling practices are integral to the prevention of typhoid, along with appropriate antibiotic use and vaccination.

- Emerging antibiotic resistant and extensively drug resistant strains of Salmonella Typhi are making treatment of typhoid more complicated and expensive.

- $\quad$ Several new typhoid vaccines are in various stages of development with particular interest in the typhoid conjugate vaccines (TCVs). One TCV has received WHO prequalification (Typbar $\mathrm{TCV}^{\mathrm{TM}}$ ) and the results of ongoing large field trials of this vaccine will inform implementation.

- $\quad$ Recent studies have shown an increase in rates of paratyphoid fever which may increase further with more widespread use of TCVs. Currently there is no licensed vaccine for paratyphoid fever.

- $\quad$ Together with improvements in water and sanitation, widespread use of TCVs should improve control of typhoid fever in the coming years. 


\section{Introduction}

Typhoid fever is caused by Salmonella enterica serovar Typhi (S. Typhi) and paratyphoid fever is caused by Salmonella enterica serovars Paratyphi A, B and C (S. Paratyphi). Collectively termed enteric fever, they are predominant in low resource settings and cause clinically indistinguishable symptoms of fever, flu-like symptoms with chills, dull frontal headache, malaise, anorexia, nausea and abdominal discomfort, and in severe cases intestinal perforation and neurological complications. Blood culture is the gold standard for diagnosis, but has limited sensitivity [1]. The mainstay of treatment is antibiotic therapy and is usually prescribed empirically but with increasing antimicrobial resistance and a limited pool of treatment options, effective treatment is becoming increasingly challenging [2]. Vaccination can be an effective measure to prevent disease, coupled with ongoing efforts to improve water, sanitation and hygiene. The World Health Organization (WHO) recommended programmatic use of typhoid vaccines in 2008 , but due to lack of funding to support vaccination, this was not implemented at country level [3]. The importance of vaccination as a preventive measure has regained attention with increasing antimicrobial resistance. More recently, in 2018, the WHO has recommended the use of the new generation of typhoid conjugate vaccines [4].

In this review, we summarize the recent advances in our understanding of enteric fever, primarily focusing on epidemiology, water, sanitation and hygiene efforts, cost of illness, treatment and antimicrobial resistance (AMR), as well as vaccination and vaccine developments.

\section{Epidemiology}

The global burden of typhoid fever, in the year 2000, was estimated to be around 21 million with 200,000 deaths [5]. Age-standardized incidences have decreased by 54.9\% (53.4- 56.5) from 1990 to 2017 likely due to improvements in economy, infrastructure, food handling practices and increased access to antibiotics [6]. Nonetheless, typhoid fever continues to pose a considerable problem. More recent estimates show that typhoid fever may cause between $11.9-26.9$ million cases and $129-135.9$ thousand deaths each year (Table 1) [6, $7,8,9]$.

\subsection{Regional Variation}

Earlier global estimates showed Asia to have high burden of disease ( $>100$ cases/100,000), and Africa, Oceania and Latin America/Caribbean to have medium burden of disease (10 100 cases/100,000) [5]. Estimates were largely based on vaccine trials and by the nature of 
these studies, sites were more likely to be chosen due to the high burden of the disease and thus likely to overestimate the burden. In recent years, there has been an increase in the number of incidence studies and a better representation of the different geographic regions. In the Global Burden of Disease Study (GBD 2017), South Asia super-region showed a remarkably high standardized incidence rate of 549 (481-625) cases per 100,000 personyears and the largest number of cases, accounting for $71.8 \%$ of the global burden [6]. The Southeast Asia, East Asia and Oceania super-region and sub-Saharan Africa also showed high burden accounting for $14.1 \%$ and $12.1 \%$ of the global typhoid cases. The GBD 2017 high income super-region is estimated to have the lowest burden of the disease. In contrast with the earlier estimates, recent data show a high incidence of typhoid fever in Africa. The Typhoid Surveillance in Africa Program established 13 surveillance sites in 10 countries in Africa and found that typhoid fever and invasive non-typhoidal salmonella (iNTS) were a major cause of invasive bacterial disease [10]. Antillon and colleagues also predicted Central Africa to have the highest incidence of typhoid globally [9]. Studies by Mogasale and colleagues [7] and by Kim and colleagues [11], on the other hand, suggest that central and eastern sub-Saharan Africa, and South Asia have the highest incidence of disease globally. However, countries still lack quality surveillance data. Data from only a few countries in a region may overestimate the burden and the uncertainly around estimates is also greater. Nonetheless, these studies help identify the regions and countries at risk of typhoid and can help countries in decision making regarding prevention and control of typhoid fever.

There is marked variation in the typhoid burden between countries in a region and even within a country. For examples, the Diseases of Most Impoverished Program described the annual typhoid incidence ranging from 24.2 in Vietnam to 493.5 per 100,000 in India [12], and in the Typhoid Surveillance in Africa Program, the adjusted incidence rate ranged from 0 in Sudan to 383 per 100,000 person years in Burkina Faso [10]. Most burden data represent certain regions within a country and may not represent the entire country.

\subsection{Incidence in Children}

Children have the highest incidence of typhoid fever. GBD 2017 noted that the highest incidence was in the 5-9 year age group [6]. Antillon and colleagues estimated a high incidence rate among children aged $2-4$ years and a relatively lower incidence rate among those under-2 years of age or over-15 years [9]. Similarly, Marks and colleagues also observed the highest incidence rates of typhoid fever in the 15 year and younger age group with peaks at 2-4 years of age or 5-14 years varying across the study sites [10]. Typhoid fever incidence has been described to follow a sigmoid curve with low incidence in the neonatal/infant period and rising with age, with a plateau in older adults [13]. This represents the low exposure to typhoid in the early infant period and increasing environmental exposure with age before it plateaus. Some studies have shown differences in typhoid burden within the different age groups depending on the overall burden of the region. The GBD 2017 study found that the incidence of typhoid fever was concentrated in 
children in the high incidence regions and that the incidence was more broadly distributed across the age groups in the low-incidence regions [6]. Antillon and colleagues, on the other hand, associated a peak incidence at 2-4 years of age with high overall incidence of typhoid and a slight peak among those aged 5-14 years was associated with overall low incidence [9]. In a systematic review and meta-analysis of pediatric enteric fever in Africa, the youngest age group contributed to the lowest proportion of cases of enteric fever, while in Asia there was marked heterogenicity between the different pediatric age groups across different studies [14]. The overall burden of typhoid fever in children is still, however, likely underestimated. The clinical suspicion of the disease is generally low in young children and diagnostic testing is not sought routinely [14]. Further, difficulties in drawing adequate volumes of blood and low sensitivity of the diagnostic blood culture add to difficulties in accurate diagnosis.

\subsection{Incidence of Paratyphoid Fever}

A systematic analysis of results from the GBD 2017 study highlighted a lack of reliable data regarding rates of paratyphoid fever. A paucity of national-level reporting of paratyphoid fever rates and the failure of individual studies to differentiate between $S$. Paratyphi A, B and $C$ leaves potential gaps in understanding and estimation of paratyphoid fever incidence. There were an estimated 3.4 million $(2.7-4.2)$ cases of paratyphoid fever and 19,000 deaths attributed to paratyphoid fever in 2017 [6]. Most cases are caused by S. Paratyphi A, and disease caused by S. Paratyphi B or C is rarely reported. Studies published in the past 20 years have shown an increase in paratyphoid fever. Ochiai and colleagues reported a higher incidence of Salmonella Paratyphi A (64\%) than Salmonella Typhi in China [15]. An increasing incidence of $S$. Paratyphi A has also been documented in studies from India [16, 17] and Nepal [18]. Salmonella Typhi accounts for an estimated 76.3\% (71.8-80.5) of cases of enteric fever and the majority of the remaining cases currently attributed to $S$. Paratyphi A [6]. Growing rates of paratyphoid fever are of concern. Little is known about the probable cause for this increase. Currently, available vaccines do not protect against infection caused by $S$. Paratyphi $A$. With the current drive towards vaccination against $S$. Typhi, it will be important to monitor the incidence of paratyphoid fever because of theoretical risk of replacement.

\section{Transmission of Enteric Fever}

Typhoid fever is a systemic illness transmitted by the fecal-oral route through contaminated food or water. Contaminated water contributes to the frequent outbreaks of typhoid fever throughout the world [19]. In Southeast Asia and sub-Saharan Africa, where there is limited access to clean water, and poor sanitation and hygiene infrastructure, more cases of typhoid and typhoid related deaths are seen [20].

S. Typhi and S. Paratyphi are exclusively human pathogens. Chronically infected hosts, although asymptomatic can serve as a reservoir for typhoid by shedding the bacteria in their 
feces [21]. Household level hygiene practices, food and water handling practices along with close contact with the index case play an important role in transmission [22]. Contamination of the broader environment, such as pollution of the water supply, is defined as long cycle transmission whereas contamination of food and water in the immediate environment is short cycle transmission, both of which play an important role in increasing the burden of the disease [23].

\subsection{Water, Sanitation and Hygiene}

In sub-Saharan Africa and Asia, nine out of ten of the 785 million people still used unimproved sources of water or surface water in 2017. Open defecation was practiced by $18 \%$ of the rural population and $1 \%$ of the urban population in these regions. Thirty nine countries, mostly from sub-Saharan Africa have recorded an increase in open defecation, accounting for total 49 million people. Two billion people, mostly from sub-Saharan Africa and Asia lacked access to basic sanitation services in 2017. Eighteen per cent of the global population (1.4 billion people) had no hand washing facilities at all [24].

An intermittent water supply poses a greater risk to the contamination of water as compared with continuous supply of water. When pressure in a municipal water supply drops, material surrounding the pipes, contaminated with sewage, can enter the clean water supply [25]. Kumpel and colleagues found that, when there was low pressure in water pipes (<10 psi), elevated bacterial contamination of the water was detected. Households which received a continuous water supply were less likely to have Escherichia coli $(0.7 \%)$ detected compared with households which received an intermittent supply (31.7\%). Three years after provision of continuous water supply, these households were $42 \%$ less likely to report at least one case of typhoid fever $[25,26]$.

Provision of clean drinking water, adequate sanitation and safe food handling practices, along with vaccination, is integral for the prevention of typhoid. Water, sanitation and hygiene practices (WASH) are the critical components of prevention of typhoid fever, especially in the low and middle economic countries where the burden of typhoid is very high [27]. Improved sanitation and availability of safe drinking water has been achieved in developed countries but still remains a challenge in most low and lower middle income countries. In the late $19^{\text {th }}$ and early $20^{\text {th }}$ centuries implementation of strategies to improve the quality of drinking water helped in reduction of typhoid related mortality by a mean of $78 \%$. According to Cutler and colleagues, filtration combined with chlorination of water helped in reducing total typhoid fever mortality by $25 \%$, and total mortality by $13 \%$ [28].

Household measures including hand washing with soap, safe food handling, treatment of drinking water with chlorination or filtration and safe water storage are recommended for prevention of transmission of enteric infections. Similarly, discouraging open defecation, construction of proper toilets and education on hygiene practices also helps in decreasing 
the burden of the disease [29]. One of the aims of the United Nations Sustainable Development Goals is to reduce inequality related to WASH. The goals set out to achieve this by providing safe and clean drinking water universally, adequate access to sanitation and hygiene and to end open defecation by 2030 [24]. Availability of clean drinking water and hygiene practices can reduce outbreaks of typhoid [19]. Introduction of clean water and sewage management can lead to decreases in the morbidity and mortality related to various fecal-oral infections including typhoid [20]

\section{Treatment and Antimicrobial Resistance}

After the introduction of first line antimicrobials (chloramphenicol, ampicillin and trimethoprim/sulfamethoxazole), the mortality due to typhoid fever reduced to around $1 \%$, from $10-30 \%$ in the pre-antibiotic era. Resistance to the first line antibiotics (known as multidrug resistant or MDR typhoid) emerged in South and South-east Asia in the 1900s. Fluoroquinolones and broad spectrum cephalosporins were recommended as alternative second-line treatment options and formally advocated by the WHO in $2003[5,8,30]$. Figure 1 summarizes the global trends in resistance to antimicrobials used to treat typhoid.

Recently, the proportion of MDR typhoid cases has decreased in certain regions and in Asia it is approaching zero, likely due to the disuse of the first line antibiotics. The Surveillance of Enteric fever in Asia Project (SEAP) found only a small proportion of MDR strains in India, Nepal and Bangladesh, while a majority in Pakistan still showed multidrug resistance [31]. The scenario in Africa has been different. MDR typhoid is still prevalent and has been associated with typhoid epidemics in the region [32, 33]. Results from the Typhoid Fever Surveillance in Africa Program showed that $47 \%$ of $S$. Typhi isolates were resistant to the first line antibiotics [10].

\subsection{Fluoroquinolones}

Fluoroquinolones such as ciprofloxacin and ofloxacin were successful in the treatment of MDR typhoid, but with their widespread use, reduced susceptibility and resistance to fluoroquinolones has ensued [34, 35]. Fluoroquinolone resistance in S. Typhi is most commonly associated with single nucleotide polymorphisms (SNPs) in gyrA [36]. SNPs have also been reported in $\operatorname{gyr} B$, parC and parE. Triple mutations with SNPs in $g y r A$ and parC are associated with high levels of ciprofloxacin resistance and are particularly seen in the H58 clonal population [36]. Resistance to fluoroquinolones has been reported from multiple countries across the globe [37, 38, 39, 40, 41, 42]. In South Asia, over 80 percent of S. Typhi were non-susceptible to fluoroquinolones [31]. A recent study from Nepal reported highlevel fluoroquinolone resistance even to fourth generation fluoroquinolones associated with a new subclade of $\mathrm{S}$. Typhi-H58 $[42,43]$. The H58 subclade is predominant in Asia and has spread across Africa and Oceania displacing other lineages [44]. And although fluoroquinolone non-susceptibility is currently low in Africa, it is on the rise. In 2017, the 
WHO also listed fluoroquinolone resistant Salmonella species as a priority pathogen that poses a substantial threat to morbidity and mortality [45].

\subsection{Cephalosporins}

Third generation cephalosporins such as oral cefixime and parenteral ceftriaxone/cefotaxime are commonly used empirically for the treatment of enteric fever, especially since the emergence of fluoroquinolone non-susceptible $S$. Typhi. Sporadic cases of $S$. Typhi resistant to the third generation cephalosporins have been reported. Resistance is mediated by extended-spectrum beta-lactamases and is usually plasmid-borne [46]. Recently, the emergence and spread of an extensively drug resistant (XDR) S. Typhi clone has been reported from Sindh Province, Pakistan. XDR S. Typhi is resistant to first-line antimicrobials as well as fluoroquinolones and third-generation cephalosporins. The XDR isolates were of $\mathrm{H} 58$ lineage with an additional IncY plasmid containing blaCTX-M15 and qnrS genes, in addition to the multiple resistant genes including blaTEM-1 (ampicillin resistance), dfrA7, sul1, sul2 (trimethoprim-sulfamethoxazole resistance), catA1 (chloramphenicol resistance), strAB (streptomycin resistance) genes and DNA gyrase (gyrA and gyrB) and topoisomerase IV (parC and parE) genes (fluoroquinolone resistance) [2].

\subsection{Azithromycin}

Azithromycin is an effective drug for the treatment of enteric fever and is still effective against the cephalosporin non-susceptible strains of $S$. Typhi. There have been sporadic reports of resistance to azithromycin [47, 48], and this is of concern given its widespread use in the outpatient management of typhoid fever and other systemic infections. Azithromycin treatment produces higher intracellular concentrations than serum levels of the antibiotic and it is thus difficult to interpret laboratory azithromycin sensitivity for S. Typhi [49]. Resistance to azithromycin is associated with ereA, $m s r D$, and msrA genes [23].

\subsection{Advances in Antibiotic Therapy}

Newer antimicrobials, carbapenems (e.g. meropenem or faropenem) or tigecycline, are effective against $S$. Typhi, and should be reserved for infections with XDR strains of the bacteria [50]. Aztreonam has been effective in small clinical trials, and can also be used as potential third line treatment for typhoid [51].

Researchers are exploring dual antibiotic therapy as a potential strategy to help control emerging antimicrobial resistance. Interventional studies have been conducted examining the efficacy of combined antibiotic therapies for the treatment of typhoid. A three-way comparison was studied between azithromycin, ofloxacin and a combination of azithromycin and ofloxacin in Vietnam. The combination therapy did not prove superior to monotherapy [52]. In a comparative trial conducted in Nepal, the combination of third generation cephalosporin and azithromycin was found to be superior to monotherapy [53]. 
These findings do not provide conclusive evidence to support dual therapy to improve effectiveness or reduce emergence of resistance.

\section{Typhoid Vaccines}

\subsection{Why Typhoid Vaccination is Necessary}

As discussed above, many low and middle income countries have inadequate water and sanitation systems, allowing the spread of typhoid and it may be generations before these systems have improved sufficiently to eliminate endemic enteric fever. While antibiotics have significantly decreased the disease burden and mortality, antimicrobial resistance has emerged as a serious problem in controlling disease. Vaccination may be a way to reduce reliance on antibiotics and protect from increasing resistance going forward. Peaks in interest in typhoid vaccination have coincided with worries over antibiotic resistance. The chloramphenicol-resistant typhoid outbreak in Mexico in the early 1970's resulted in renewed focus on vaccine research, this was followed shortly by development of the live oral vaccine, Ty21a, and non-denatured Vi polysaccharide vaccine [54]. Recently interest in deployment of vaccine programmes has aligned with spread of resistant disease since the 1990 's and the emergence of the XDR S. Typhi strain causing the ongoing outbreak in Pakistan $[2,40]$.

\subsection{Early Typhoid Vaccine Attempts}

Typhoid vaccines have been in existence for over 100 years. In 1886, Wright in England and Pfeiffer and Kolle in Germany developed a typhoid vaccine at about the same time, but independently of one another. These first vaccines were made using heat-killed whole cell Salmonella Typhi and significant side effects were noted in the first subjects [55]. Carroll and Vedder trialed an oral, heat-inactivated typhoid vaccine in 1904. Initially their heatinactivation technique was flawed and several study volunteers developed typhoid fever including one of the study supervisors [56]. Wright believed that a vaccine for typhoid could save thousands of lives and he pressed the British government to vaccinate soldiers in World War One. Despite some public reservations about typhoid vaccination it was offered to British WWI soldiers. Initially a typhoid only whole cell vaccine was given to soldiers and in 1916 a combination vaccine (TAB) against S. Paratyphi A and S. Paratyphi B as well as S. Typhi was introduced [57]. This was the first war when more soldiers died from combat than from disease [58]. However it was not until the 1960's that large field studies proved the efficacy of the typhoid whole cell vaccine [55].

\subsection{Inactivated Whole Cell Typhoid Vaccine}

Several preparations of inactivated whole cell typhoid vaccine have been developed since the initial 1886 heat-inactivated vaccine. In field studies the whole cell vaccine showed efficacy of $65 \%$ against enteric fever [59]. However it has fallen out of use due to its high rate of side effects, with up to $34 \%$ reporting side effects including fever and disease-like 
symptoms [60]. The other available vaccines offer at least similar levels of protection without the significant side effect profile.

\subsection{Current Vaccines}

Presently there are three types of typhoid vaccines available for use, the live oral Ty21a vaccine, parenteral Vi polysaccharide vaccine and parenteral typhoid conjugate vaccine (TCV). Since $2008 \mathrm{WHO}$ has recommended the use of Ty21A and Vi polysaccharide vaccines to control typhoid fever but only Vi polysaccharide vaccine (from a single manufacturer) is WHO prequalified [3]. The 2018 WHO position paper states that TCV is now preferred at all ages, however Vi polysaccharide vaccine and Ty21a can still be considered. Figure 2 presents the efficacy of current typhoid vaccines based on results from large-scale field trials that used culture positive typhoid fever as the primary end-point. WHO recommends that a typhoid vaccine be included in the primary vaccination schedule in endemic countries with a high burden of disease and that typhoid vaccines can be considered to control outbreaks and in humanitarian emergencies (Table 2) [4].

\subsection{Live-Attenuated Ty21a Vaccine}

Ty21a live-attenuated oral vaccine was first licensed for use in the 1980's. It is a live vaccine which contains a mutated strain of Salmonella Typhi (Ty21a). When Ty21a is exposed to galactose, the resulting cell wall lysis produces an avirulent strain of $S$. Typhi [61]. Given the pathophysiology of typhoid fever, an oral vaccine which could target the local, cell-mediated and systemic antibody immunity systems was thought to be more beneficial than a parenteral vaccine which lacked a local response [62]. Ty21a vaccine has the advantage of being given orally in three or four doses over 5 days. The major drawback is that it is not recommended for use in children under 6 years of age, and even at this age, there are few children who will swallow the capsules. In endemic countries, repeat vaccination is advised every three years [63].

Human challenge studies were used to show safety and efficacy of the Ty21a vaccine prior to field studies [64]. A randomized placebo-controlled trial involving 109,000 children in Chile showed $67 \%$ efficacy of the enteric capsule vaccine. Another randomized, double-blind trial in Indonesia showed efficacy of $53 \%$ with a liquid formulation which would be suitable for younger children (no longer available) and $42 \%$ with the enteric capsules (Figure 3) [65, 66]. The 2018 Cochrane review reported efficacy of $45 \%$ one year post Ty 21 a vaccination and $59 \%$ at two years. This increase in efficacy is presumed to be the result of a natural boosting effect in endemic areas [67].

While efficacy rates for Ty21a may be similar to the whole-cell vaccine the major advantage of Ty21a is the side effect profile. Ty21a is much better tolerated, with similar levels of side effects, including fever, seen among the vaccine and control groups in an Indonesian study 
[66]. Levine et al showed that there was no increase in fever or intestinal illness among those given the vaccine versus controls [65].

\subsection{Vi Polysaccharide Vaccine}

Salmonella Typhi is usually encapsulated in a polysaccharide layer, the Vi capsular antigen. This Vi polysaccharide acts both as a virulence factor and a protective antigen. Vi-deficient strains of $S$. Typhi are far more susceptible to host immune responses. Vi-specific antibody also acts as a protective antigen and can direct and activate complement on the S. Typhi cell surface $[68,69]$.

A subunit vaccine was developed in the 1980's consisting of purified Vi antigen. The Vi polysaccharide vaccine is available as a single-dose, injectable vaccine. It is not licensed for children under two years of age. Because of the relatively short-lived immune response repeat doses are recommended every 2-3 years. One formulation of Vi vaccine has received WHO prequalification and it is licensed in over 90 countries [20]. Vi polysaccharide vaccine has been used in routine vaccination programs in endemic areas and also has been shown to be effective as part of vaccination campaigns following natural disasters $[20,70,71]$.

The Vi polysaccharide vaccine has been tested in several large field studies. Efficacy rates vary from $64 \%$ to $72 \%$. Over 11,000 children were involved in a randomized double-blind trial in South Africa which showed efficacy of 64\% following 21 months of surveillance [72]. Efficacy of $69 \%$ was reported in a study of 131,271 children and adults in China [73]. In Nepal efficacy of $72 \%$ in preventing culture-positive typhoid fever was reported in a study of over 6000 participants from 5 to 44 years of age [74]. A large cluster-randomized trial in India reported effectiveness of $61 \%$ in adults and children over two years of age. Mass vaccination with $\mathrm{Vi}$ vaccine also offers some protection to unvaccinated members of the community with $44 \%$ effectiveness reported among non-vaccinated people living in areas of vaccination. Eighty per cent protection was reported in children between 2 and 5 years of age [75]. Khan et al reported 57\% effectiveness in Pakistani children aged 5-16 years. Unlike the Indian study they showed that there was no significant protection provided to 2-5 year old children who were given the Vi polysaccharide vaccine versus controls (Figure 4) [76].

The Vi vaccine is generally well tolerated, with no significant side effects reported in any of the above studies. Local erythema and swelling were reported as the most common side effects with significant fever reported in less than $1 \%$ of cases $[72,73,77]$. The side effect profile and the ease of administration, just one injection, are the main advantages of $\mathrm{Vi}$ vaccine over the previously available vaccines.

The two main drawbacks to the Vi vaccine are that it is not licensed for children under two years of age and it does not induce a booster response. The Vi vaccine, like most polysaccharide vaccines, are T-lymphocyte independent antigens which induce an 
inadequate immune response in young children and fail to induce B cell memory. For this reason it is advised that the vaccine is repeated every two to three years to maintain adequate immunity among those at ongoing risk $[78,79]$. This has been shown in practice with the French Armed Forces changing their Vi vaccination frequency from five to three years after an outbreak of typhoid. The risk of typhoid was twice as high in the army personnel who were vaccinated longer than three years before the outbreak [80]. Vi antibody falls slowly after an initial peak post vaccine, one study reported that almost two thirds of participants had antibody levels below their estimated protective cut-off 27 months after vaccination [81]. These findings have led the WHO to recommend revaccination every three years in endemic areas [3].

A new synthetic Vi polysaccharide vaccine has been developed. The polygalacturonic acid base of this synthetic vaccine shares the same backbone as the Vi polysaccharide antigen. Studies in mice have shown higher immunogenicity than seen with the standard Vi vaccine. The synthetic vaccine demonstrated a booster response when a second dose was given, which the authors hope will make the vaccine effective in children under two years of age [82].

\subsection{Typhoid Conjugate Vaccines}

In 1987, studies in animal models showed improved immunogenicity with conjugation of the Vi polysaccharide to a protein carrier [83]. Currently there are several typhoid conjugate vaccines (TCVs) in various stages of development. WHO recommends the use of TCVs in endemic areas and it is the preferred vaccine in children from 6 months of age [4].

\subsubsection{Vi-rEPA Typhoid Conjugate Vaccine}

The Vi polysaccharide was bound to a recombinant protein derived from Pseudomonas aeruginosa exotoxin $\mathrm{A}$ (Vi-rEPA). This produced a typhoid conjugate vaccine which has shown greater immunogenicity in animal studies than Vi alone [84]. A study published in 1999 evaluated two Vi-rEPA vaccination preparations in Vietnam. It showed these vaccines were well tolerated with no significant side effects. This study compared the two Vi-rEPA vaccines with a Vi polysaccharide vaccine. All three vaccines showed a significant rise in IgG $\mathrm{Vi}$ antibody which persisted at 26 weeks post vaccination. In 5-14 year old children, one VirEPA formulation showed a significantly higher IgG level 26 weeks after two injections compared with one injection of the Vi polysaccharide vaccine. This study also showed that the Vi-rEPA vaccines elicited significant antibody responses in younger children. At 26 weeks post vaccination, one Vi-rEPA preparation produced higher antibody responses in the 2-4 year old group when compared with 5-14 year old children who were given the $\mathrm{Vi}$ polysaccharide vaccine [85]. In 2004, a placebo-controlled randomized trial reported the efficacy of Vi-rEPA to be $89 \%$ among 2-5 year old children over a 46 month period [86]. A second RCT showed efficacy of $91 \%$ and also that anti-Vi IgG increased by a factor of 10 following a second dose of Vi-rEPA in all children (Figure 5) [87]. 
Thiem et al showed that Vi-rEPA was safe in infants over 6 months of age. It was given alongside the routine vaccination schedule without any significant side effects and no interference with other vaccine responses were seen. Ninety percent of infants who were given Vi-rEPA had anti-Vi IgG levels above the estimated level of protection [88]. Despite the promising clinical data, Vi-rEPA has not been licensed and other conjugate vaccines have achieved licensure instead.

\subsubsection{Vi-Tetanus Toxoid Conjugate Vaccine}

Conjugation of Vi antigen with tetanus toxoid carrier protein has also produced effective vaccines. Prior to the December 2019 publication from Shakya et al, see section 5.7.4 below, there were no published data on efficacy of Vi-tetanus toxoid (Vi-TT) TCVs in endemic areas [89]. A 2018 Cochrane review of typhoid vaccines highlighted the need for further data on efficacy of Vi-TT in field trials [90].

\subsubsection{PedaTyph ${ }^{\text {TM }}$}

A Vi-tetanus toxoid conjugate vaccine (PedaTyph ${ }^{\text {TM }}$ ) has been licensed for use in India. This vaccine demonstrated $100 \%$ efficacy in preventing typhoid in a study involving 1,765 Indian children over 6 months of age. No typhoid fever cases were found in the vaccine group over 12 month follow up compared with a typhoid rate of $1.27 \%$ in the control group. Significant antibody responses ( 4 fold rise from baseline) were found in $83 \%$ of vaccinated children at 12 months post vaccination [91]. PedaTyph ${ }^{\text {TM }}$ is licensed and marketed only in India (Figure 6) [4]. The WHO Strategic Advisory Group of Experts (SAGE) working group on typhoid vaccines reported "the limited publically available pre-licensure data." The working group stated that the "quality of evidence for this vaccine was assessed as very low due to apparent methodological weaknesses in the trials and lack of additional data for in-depth review." The SAGE group stated that "no conclusions can therefore be made about the potential use of this vaccine" [92].

\subsubsection{Typbar TCV ${ }^{\text {тm }}$}

Another Vi-tetanus toxoid TCV (Typbar TCV ${ }^{\mathrm{TM}}$ ) was licensed in India in 2013. Typbar-TCV ${ }^{\mathrm{TM}}$ was the first TCV to receive WHO prequalification [93, 94]. Mohan et al enrolled 654 participants from 2-45 years of age into a phase III RCT comparing Vi-TT with Vi polysaccharide vaccine. This study aimed to assess the safety and immunogenicity of Typbar $\mathrm{TCV}^{\mathrm{TM}}$. Higher $\mathrm{Vi-IgG}$ antibody responses were shown in the $\mathrm{Vi-TT}$ group across all age groups and these persisted at two year follow up. There were also 327 children from 6-23 months who were enrolled in an open-label add-on study without the Vi polysaccharide comparator. Ninety eight percent of children 6-23 months showed seroconversion (four-fold rise from baseline) 42 days post-vaccine, this decreased to $59 \%$ at two years. Overall the vaccine was well tolerated and induced strong booster responses in all ages [90]. Using data from this RCT, a novel approach was employed to estimate the efficacy of Typbar TCV ${ }^{\mathrm{TM}}$. 
Voysey et al utilized the immunogenicity and demographic data from Mohan et al's RCT to estimate the incidence of typhoid infection using serological data (seroincidence) rather than blood culture results. Generally after vaccination antibody levels rise to a peak at 4-6 weeks, following this they decline sharply and then plateau. If infection occurs following vaccination this pattern is interrupted, antibody levels will rise when they are expected to fall. Voysey et al looked for interruptions in the expected antibody levels to find those who had serological evidence of infection. Using this information and a mixed modelling system Voysey et al classified those who had serological evidence of infection. They used this to calculate serological efficacy of vaccination (seroefficacy). They reported seroefficacy of Typbar TCV ${ }^{\mathrm{TM}}$ at $85 \%$ [95].

Given the cost and time involved in large-scale field studies, other methods have been used to prove the efficacy of Vi-TT TCV. A randomized, control trial of healthy adult volunteers in a non-endemic area was used to evaluate efficacy. This study used the previously established human-challenge model to estimate vaccine efficacy [96]. Participants were randomly assigned to receive $\mathrm{Vi-TT}$, Vi polysaccharide or a control vaccine. One month postvaccination participants were given sodium bicarbonate solution and then challenged with wild-type oral $S$. Typhi (1-4 $\times 10^{4}$ colony forming units). Participants were monitored for symptoms of enteric fever for 21 days post-challenge. The primary endpoint was the proportion of participants diagnosed with typhoid fever using clinical and/or microbiological criteria (attack-rate). One hundred and four participants were challenged, Vi-TT significantly reduced the attack-rate for typhoid fever versus controls (35\% vs $77 \%$ ). The calculated vaccine efficacy for Vi-TT was $54.6 \%$. Seroconversion in the Vi-TT group was $100 \%$ after 28 days. The vaccine efficacy was thought to be an underestimate as the population were typhoid-naïve adults, infection risk was increased by neutralization of gastric acid and the presumed high dose of challenge, and frequent sampling meant that self-limiting infections would be detected. The efficacy in the field is expected to be higher considering that the $\mathrm{Vi}$ polysaccharide vaccine efficacy in the human challenge study was $52 \%$, which is significantly lower than that seen in field studies, supporting the impression that the challenge model is rather stringent. In post-hoc analysis, using a definition which would fit more closely to the field setting (fever followed by microbiological confirmation of typhoid) the efficacy of Vi-TT increased to 87\% [97]. This Vi-TT vaccine has been shown to be safe when given with the measles vaccine and can be co-administered at 9 months [94].

Studies so far have shown Vi-TT conjugate vaccines to be safe and well tolerated, they can generate an immune response in children under two years of age and they have the potential for immunological memory. Currently three large studies are underway in Bangladesh, Malawi and Nepal, a cluster-randomized control trial and two individuallyrandomized control trials respectively. These studies compare Vi-TT with a geographically appropriate control vaccine and include vaccination of children from 9 months to 16 years of age, followed for 2 years. These are the first large-scale randomized control trials 
evaluating Vi-TT in endemic settings $[98,99,100]$. In December 2019 Shakya et al reported results from the planned interim analysis of a study involving over 20,000 Nepali children. Typbar TCV ${ }^{\mathrm{TM}}$ showed protective vaccine efficacy of $81.6 \%$ during 15 months of follow up, this study is continuing to complete 2 full years of follow-up for these children [89].

\section{Cost of IIIness and Cost effectiveness}

\subsection{Cost of Typhoid}

In addition to improvements in sanitation and food hygiene, along with the provision of clean drinking water, vaccines can help reduce the burden of typhoid fever [101]. In order to support policy decisions on implementation of typhoid vaccines, data regarding the burden of typhoid, cost of illness of the disease and cost effectiveness of vaccination are required. However, there are limited data on the economic burden of typhoid and economic benefits of typhoid vaccination. There is also a great variability in cost estimates due to the differences in the sample population case definitions, data sources etc. [102]. Total cost of illness of typhoid is a combination of direct medical costs, direct non-medical costs including travel, food and accommodation for the accompanying person and the indirect costs including loss of wages due to absence from work [101]. Bahl et al, studied the incidence and cost of illness in an urban slum, in Delhi, India and found that mean cost per episode of blood culture-confirmed typhoid fever was around $\$ 100$ per case and hospitalization increased the costs by several fold. They also found that the cost for patients who did not respond quickly to antibiotics was five times higher than those who did respond [102].

Across various studies examining economic issues in typhoid cases, inpatient costs were higher than outpatient costs. In India, costs per outpatient case ranged from $\$ 16$ to $\$ 74$ and inpatient costs from $\$ 159$ to $\$ 636$. In Nepal, the average cost per hospitalized case was found to be $\$ 233$ and the outpatient cost to be $\$ 39$ [103]. An incidence-based cost of illness evaluation done by Riewpaiboon et al at Pemba, Zanzibar showed that the cost of treatment for a typhoid fever episode was US\$21.97. Overall mean costs per episode, including the direct costs before, during, and after hospitalization and productivity costs from lost wages was US\$154.47. The majority of the total cost of typhoid infection arises from productivity costs due to lost wages (83\%) [104].

A community-based study of the private and public costs, paid by the households and the government respectively, in five Asian countries (by Poulos et al) found that private costs of treatment were higher than public costs, posing a burden on the household. The average private cost of a non-hospitalized case was $13 \%$ of the average monthly household income in Kolkata, 23\% in North Jakarta, and 55\% in Hechi. The average private cost of a hospitalized case was $35 \%$ of monthly-income in Kolkata and over $100 \%$ in North Jakarta and Hechi [104].

\subsection{Cost Effectiveness of Vaccine}


Antillon and colleagues evaluated the cost effectiveness of typhoid conjugate vaccines in three urban settings and two rural settings by simulating TCV delivery by five strategies, using a dynamic model of typhoid transmission. They found that routine vaccination with TCV would be cost effective in most settings, and together with a catch up campaign this strategy would avert the most disability-adjusted life years (DALYs) [105]. Another study performed by Bilcke and colleagues evaluated three TCV delivery strategies, with routine vaccination at 9 months of age alone or in combination with catch up vaccination to either 5 or 15 years of age. Routine vaccination with a catch up campaign was optimal and it would be cost-effective in countries with incidence of 300 or more typhoid cases per 100,000 person-years [106].

\section{Future Enteric Fever Vaccines}

\subsection{New Typhoid Conjugate Vaccines}

There is much interest in the use of TCVs to assist in the control of enteric fever in high burden areas. In addition to those already licensed there are several other TCVs in various stages of development. These include Vi-CRM197 developed by GSK (now partnered with an Indian manufacturer), a Vi-TT vaccine from Zydus Cadila and Vi-DT (diphtheria toxoid) from the International Vaccine Institute (with manufacturing partners) [94]. Vi-CRM197 is a TCV where the polysaccharide antigen is conjugated to the non-toxic mutant of diphtheria toxin CRM197 [107]. Vi-CRM197 is reported to be safe and immunogenic in endemic populations including infants 6-8 weeks of age. However it did not show a significant booster response when a second dose was given and in a Pakistani cohort there was no increase seen in antiVi antibody at six months post vaccine [108]. Further development is ongoing.

A plant-derived polysaccharide vaccine has undergone phase 1 testing, it uses fruit pectin from citrus peel as a carbohydrate backbone instead of $\mathrm{Vi}$. This $\mathrm{O}$-acetylated pectin conjugate vaccine was shown to be safe in healthy adults, $64 \%$ of participants had a significant immunological response. The O-acetylated pectin conjugate vaccine produced lower levels of anti-Vi IgG response when comparted with Vi-rEPA [109].

Vi-negative strains of $S$. Typhi have been reported in small numbers of isolates in Asian countries. $\mathrm{Vi}$ vaccine and the $\mathrm{Vi}$-conjugate vaccines rely on the presence of $\mathrm{Vi}$ antigen for immunity so this creates another potential issue in vaccine development [110, 111, 112].

\subsection{Live Attenuated Vaccines}

M01ZH09 is an experimental oral live-attenuated vaccine with two targeted deletions. M01ZH09 has been shown to be safe and immunogenic in phase I and II trials $[113,114]$. However during a randomized, placebo-controlled, double-blind trial using a human challenge model M01ZH09 did not confer any benefit versus placebo. When post hoc analysis adjusted for baseline anti-Vi IgG the rate of clinical typhoid in the M01ZH09 group 
was $51 \%$ lower than the placebo group. Further studies are required to explore the significance of this post hoc analysis [115].

Four other live, attenuated, oral vaccine strains (CVD 908, CVD 909, CVD 910, and CVD 915) have been developed at the Center for Vaccine Development, University of Maryland. All four strains have been derived from the S. Typhi Ty2 strain. CVD 909 was engineered to express Vi polysaccharide and stimulate $\mathrm{Vi}$ antibody response as well as humoral and cellmediated immune responses. CVD 909 has shown efficacy in mouse models and produced antibodies against $S$. Typhi $[116,117,118]$. CVD 909 has been used as an oral primer prior to parenteral Vi polysaccharide vaccine. This method showed non-significant increases in efficacy when compared with Vi vaccine alone. Vi-specific IgA B memory cells were significantly increased in the subjects primed with CVD 909 which led to the conclusion that oral vaccines can increase immune memory [119].

\subsection{Paratyphoid Vaccine}

There are currently no licensed paratyphoid vaccines. Enteric fever combination vaccines were previously available for use. The trivalent vaccine against typhoid, paratyphoid $A$ and paratyphoid B (TAB vaccine) contained whole cell preparations of S. Typhi, S. Paratyphi A and S. Paratyphi B. Paratyphoid vaccines were used during World War I and World War II however the efficacy of the paratyphoid vaccine elements were questionable and these vaccines were subsequently withdrawn [120].

Studies have been carried out looking at whether Ty21a provides some cross-protection against paratyphoid fever. Ty21a has been shown to elicit antibodies with cross-reactivity against $S$. Paratyphi A and B in vitro [121, 122]. In pooled results from two trials in Chile Ty21a showed $49 \%$ efficacy against S. Paratyphi B [123]. However, this effect was not repeated in a large randomized control trial in Indonesia, with no protection against $S$. Paratyphi A or B seen with Ty21a [66]. Ty21a may provide moderate protection against paratyphoid fever but the evidence is unclear.

Similar to S. Typhi, paratyphoid strains have no small-animal model and infection is restricted to humans. Because of this a human challenge model has been developed to help understand paratyphoid infection and potential protection following vaccination [124]. Population based studies in South Asia have reported $14.5-37 \%$ of enteric fever cases were identified as S. Paratyphi A [125]. With this in mind an effective paratyphoid vaccine should have a significant impact on rates of enteric fever. Several research groups are looking at developing a paratyphoid vaccine with numerous potential candidates [126]. The O-specific polysaccharide of $S$. Paratyphi $A$ is a protective antigen and a potential antigen for conjugate paratyphoid vaccines. Conjugation of O-specific polysaccharide to CRM197 carrier protein has shown bactericidal activity against $S$. Paratyphi A in mouse models [127]. Phase I and II trials of an O-specific polysaccharide conjugated to tetanus toxoid have shown 
immunogenicity against $S$. Paratyphi $A$, however there was no booster response following a second injection [128]. Pre-clinical trials of a live-attenuated oral vaccine candidate for $S$. Paratyphi A (CVD 1902) showed it to be immunogenic and phase 1 trials have been completed [129].

A live, attenuated vaccine against $S$. Paratyphi B was capable of protecting mice from $S$. Paratyphi B Java. The authors suggest that with a reduction in S. Typhi cases, S. Paratyphi B may become a more significant pathogen. Hence, a vaccine against $S$. Paratyphi $B$ may be of clinical use in the future [130].

An effective vaccine against paratyphoid strains may become more important in the future given the current incidence of paratyphoid fever and the potential for paratyphoid strains to become more prominent as $S$. Typhi cases decline.

\subsection{Invasive Non-typhoidal Salmonella}

Non-typhoidal salmonella (NTS) infection leads to a significant burden of bacteremia, with an estimated 3.4 million (range 2.1-6.5 million) cases annually. The highest incidence is reported in Africa with 227 cases [range 152-341] per 100,000 population [131]. A systematic review of invasive non-typhoidal salmonella (iNTS) in Africa estimated an overall case fatality rate of $20.6 \%$ [132, 133]. A much higher case fatality rate has been reported in HIV-positive adults at $47 \%[134]$.

Similar to the situation with the pathogens of enteric fever, MDR strains of iNTS have emerged. MDR S. Typhimurium, ST313 has caused outbreaks in several countries across subSaharan Africa [133]. With a greater understanding of the significant burden of iNTS and the emergence of MDR iNTS there has been recent interest in iNTS vaccine development. These vaccine candidates target the most common disease causing NTS serovars, $S$. Typhimurium and $S$. Enteritidis. Animal models have been used to assess potentially effective vaccine candidates including live attenuated and subunit vaccines targeting $\mathrm{O}$-antigens or other outer membrane proteins $[135,136]$.

Combination vaccines which target iNTS and typhoid fever could provide control for the important invasive Salmonella serovars in Africa [137].

\section{Conclusion}

Globally the incidence of typhoid fever is decreasing, however studies demonstrate significant ongoing burden of disease. Provision of clean drinking water, adequate sanitation and safe food handling practices are integral to the prevention of typhoid. However, many low and middle income countries have water and sanitation systems which facilitate typhoid transmission. Effective antimicrobial treatment has significantly reduced mortality from typhoid, however new XDR strains of S. Typhi are cause for concern. Vaccination remains an 
important element in managing typhoid fever. Efficacy against $S$. Typhi has been demonstrated for Ty21a and Vi polysaccharide vaccines in field studies. Newer TCVs have shown promising results in studies utilizing a human challenge model or using serological data to estimate efficacy. Currently large-scale field studies of TCVs are in progress and new typhoid vaccines are in various stages of development. Economic studies have shown that TCVs should be cost-effective when used in the primary vaccination schedule with a catch up campaign in countries with a high burden of typhoid.

Some studies have suggested an increase in the incidence of paratyphoid fever. With the current drive towards vaccination against $S$. Typhi, incidence rates of paratyphoid fever need to be monitored. There are currently no licensed paratyphoid vaccines but vaccine candidates are in development.

\section{Expert Opinion}

Our understanding of typhoid fever has progressed to a point where we have the knowledge and tools to effectively eliminate typhoid. We know that improvements to water and sanitation systems can reduce the amount of circulating bacteria. Antibiotics can treat most strains of $S$. Typhi effectively. Vaccines are available which offer some protection against typhoid fever in those areas without adequate water and sanitation systems. So why is typhoid still killing thousands of people every year? While improvements in water and sanitation have eliminated endemic typhoid in many areas, several countries are generations away from having adequate levels of water and sanitation to prevent typhoid fever. While we wait for municipal services to improve, antibiotics and vaccination are important weapons against typhoid fever.

XDR strains of $S$. Typhi and reports of sporadic azithromycin resistance mean that antibiotic treatment is becoming more complicated. Tight controls should be in place with any antibiotic use but this is especially true in this era of increasing antimicrobial resistance. Increasing use of cephalosporins and azithromycin in treating various bacterial conditions will lead to selective pressures which allow resistant strains of $S$. Typhi to thrive. Emerging antibiotic resistance has driven the need for new vaccine development. The GAVI funding window for TCVs has been open since November 2017. Several key factors need to be considered when a country is deciding on the introduction of TCVs including the burden of typhoid in a given area, the efficacy of the vaccine and the cost-effectiveness of vaccine introduction.

Incidence of typhoid will vary from area to area even within a country, and typhoid incidence has been shown to peak at different ages in different countries. Accurate incidence rates will be key when deciding on introduction of new typhoid vaccines. Incidence rates will change as populations become more urbanized and put increasing pressure on water and sanitation systems in low and middle income countries. 
Ongoing research aims to demonstrate that TCVs provide effective protection against typhoid fever in endemic settings, including providing protection to young children. The first results from a large-scale efficacy study in a WHO approved TCV were published at the end of 2019. This interim analysis showed encouraging efficacy. The final results are expected to be available in late 2020 .

Cost-effectiveness studies have suggested that including TCVs in routine vaccination schedules, combined with a catch-up campaign, would be cost-effective in several typhoid endemic areas. TCVs will become cost-effective at lower typhoid incidence rates should increasing antibiotic resistance make treatment of typhoid fever more difficult and expensive. 


\section{References}

1. Vaishnavi C. Infections of the Gastrointestinal System. Jaypee Brothers,Medical Publishers Pvt. Limited; 2013.

2. Klemm EJ, Shakoor S, Page AJ, et al. Emergence of an Extensively Drug-Resistant Salmonella enterica Serovar Typhi Clone Harboring a Promiscuous Plasmid Encoding Resistance to Fluoroquinolones and Third-Generation Cephalosporins. MBio. 2018 Feb 20;9(1). doi: 10.1128/mBio.00105-18. PubMed PMID: 29463654; PubMed Central PMCID: PMCPMC5821095.

3. World Health Organization. Typhoid vaccines: WHO position paper. Wkly Epidemiol Rec. 2008 Feb 8;83(6):49-59. PubMed PMID: 18260212; eng

fin.

4. World Health Organization. Typhoid vaccines: WHO position paper, March 2018 Recommendations. Vaccine. 2019 Jan 7;37(2):214-216. doi: 10.1016/j.vaccine.2018.04.022. PubMed PMID: 29661581; eng.

5. Crump JA, Luby SP, Mintz ED. The global burden of typhoid fever. Bull World Health Organ. 2004 May;82(5):346-53. PubMed PMID: 15298225; PubMed Central PMCID: PMCPMC2622843.

6. Typhoid GBD, Paratyphoid C. The global burden of typhoid and paratyphoid fevers: a systematic analysis for the Global Burden of Disease Study 2017. Lancet Infect Dis. 2019 Apr;19(4):369-381. doi: 10.1016/S1473-3099(18)30685-6. PubMed PMID: $30792131 ;$ PubMed Central PMCID: PMCPMC6437314.

7. Mogasale V, Maskery B, Ochiai RL, et al. Burden of typhoid fever in low-income and middle-income countries: a systematic, literature-based update with risk-factor adjustment. Lancet Glob Health. 2014 Oct;2(10):e570-80. doi: 10.1016/S2214109X(14)70301-8. PubMed PMID: 25304633.

8. Buckle GC, Walker CL, Black RE. Typhoid fever and paratyphoid fever: Systematic review to estimate global morbidity and mortality for 2010. J Glob Health. 2012 Jun;2(1):010401. doi: 10.7189/jogh.02.010401. PubMed PMID: 23198130; PubMed Central PMCID: PMCPMC3484760.

9. Antillon M, Warren JL, Crawford FW, et al. The burden of typhoid fever in low- and middle-income countries: A meta-regression approach. PLoS Negl Trop Dis. 2017 Feb;11(2):e0005376. doi: 10.1371/journal.pntd.0005376. PubMed PMID: 28241011; PubMed Central PMCID: PMCPMC5344533.

10. Marks F, von Kalckreuth $V$, Aaby $P$, et al. Incidence of invasive salmonella disease in sub-Saharan Africa: a multicentre population-based surveillance study. Lancet Glob Health. 2017 Mar;5(3):e310-e323. doi: 10.1016/S2214-109X(17)30022-0. PubMed PMID: 28193398; PubMed Central PMCID: PMCPMC5316558.

11. Kim JH, Mogasale V, Im J, et al. Updated estimates of typhoid fever burden in subSaharan Africa. Lancet Glob Health. 2017 Oct;5(10):e969. doi: 10.1016/S2214109X(17)30328-5. PubMed PMID: 28911760.

12. Ochiai RL, Acosta CJ, Danovaro-Holliday MC, et al. A study of typhoid fever in five Asian countries: disease burden and implications for controls. Bull World Health 
Organ. 2008 Apr;86(4):260-8. doi: 10.2471/blt.06.039818. PubMed PMID: 18438514; PubMed Central PMCID: PMCPMC2647431.

13. Crump JA. Progress in Typhoid Fever Epidemiology. Clin Infect Dis. 2019 Feb 15;68(Supplement_1):S4-S9. doi: 10.1093/cid/ciy846. PubMed PMID: 30767000; PubMed Central PMCID: PMCPMC6376096.

14. Britto C, Pollard AJ, Voysey M, et al. An Appraisal of the Clinical Features of Pediatric Enteric Fever: Systematic Review and Meta-analysis of the Age-Stratified Disease Occurrence. Clin Infect Dis. 2017 Jun 1;64(11):1604-1611. doi: 10.1093/cid/cix229. PubMed PMID: 28369224; PubMed Central PMCID: PMCPMC5434381. eng.

15. Ochiai RL, Wang X, von Seidlein L, et al. Salmonella paratyphi A rates, Asia. Emerg Infect Dis. 2005 Nov;11(11):1764-6. doi: 10.3201/eid1111.050168. PubMed PMID: 16318734; PubMed Central PMCID: PMCPMC3367370.

16. Sood S, Kapil A, Dash N, et al. Paratyphoid fever in India: An emerging problem. Emerg Infect Dis. 1999 May-Jun;5(3):483-4. doi: 10.3201/eid0503.990329. PubMed PMID: 10341194; PubMed Central PMCID: PMCPMC2640769.

17. Tankhiwale SS, Agrawal G, Jalgaonkar SV. An unusually high occurrence of Salmonella enterica serotype paratyphi A in patients with enteric fever. Indian J Med Res. 2003 Jan;117:10-2. PubMed PMID: 12866820.

18. Ericsson CD, Hatz C, Basnyat B, et al. Enteric (Typhoid) Fever in Travelers. Clinical Infectious Diseases. 2005;41(10):1467-1472. doi: 10.1086/497136.

19. Lee $D Y$, Lee $E$, Park $H$, et al. Availability of clean tap water and medical services prevents the incidence of typhoid Fever. Osong Public Health Res Perspect. 2013 Apr;4(2):68-71. doi: 10.1016/j.phrp.2013.03.005. PubMed PMID: 24159533; PubMed Central PMCID: PMCPMC3767100.

20. Date KA, Bentsi-Enchill A, Marks F, et al. Typhoid fever vaccination strategies. Vaccine. 2015 Jun 19;33 Suppl 3:C55-61. doi: 10.1016/j.vaccine.2015.04.028. PubMed PMID: 25902360.

21. Monack DM. Salmonella persistence and transmission strategies. Curr Opin Microbiol. 2012 Feb;15(1):100-7. doi: 10.1016/j.mib.2011.10.013. PubMed PMID: 22137596.

22. Akullian A, Ng'eno E, Matheson Al, et al. Environmental Transmission of Typhoid Fever in an Urban Slum. PLoS Negl Trop Dis. 2015 Dec;9(12):e0004212. doi: 10.1371/journal.pntd.0004212. PubMed PMID: 26633656; PubMed Central PMCID: PMCPMC4669139.

23. Gibani MM, Britto C, Pollard AJ. Typhoid and paratyphoid fever: a call to action. Curr Opin Infect Dis. 2018 Oct;31(5):440-448. doi: 10.1097/QCO.0000000000000479. PubMed PMID: 30138141; PubMed Central PMCID: PMCPMC6319573.

24. UNICEF W. Progress on household drinking water, sanitation and hygiene 2000-2017. UNICEF Report. 2019.

25. Luby SP. Urban Slums: A Supportive Ecosystem for Typhoidal Salmonellae. J Infect Dis. 2018 Nov 10;218(suppl_4):S250-S254. doi: 10.1093/infdis/jiy324. PubMed PMID: 30060082; PubMed Central PMCID: PMCPMC6226803.

26. Kumpel E, Nelson KL. Mechanisms affecting water quality in an intermittent piped water supply. Environ Sci Technol. 2014;48(5):2766-75. doi: 10.1021/es405054u. PubMed PMID: 24459990. 
27. Brown J, Cairncross S, Ensink JH. Water, sanitation, hygiene and enteric infections in children. Arch Dis Child. 2013 Aug;98(8):629-34. doi: 10.1136/archdischild-2011301528. PubMed PMID: 23761692; PubMed Central PMCID: PMCPMC3717778.

28. Cutler $D$, Miller $G$. The role of public health improvements in health advances: the twentieth-century United States. Demography. 2005 Feb;42(1):1-22. doi: 10.1353/dem.2005.0002. PubMed PMID: 15782893.

29. Bennett SD, Lowther SA, Chingoli F, et al. Assessment of water, sanitation and hygiene interventions in response to an outbreak of typhoid fever in Neno District, Malawi. PLoS One. 2018;13(2):e0193348. doi: 10.1371/journal.pone.0193348. PubMed PMID: 29474394; PubMed Central PMCID: PMCPMC5825105.

30. World Health Organisation. Vaccine-Preventable Diseases Surveillance Standards: Typhoid and other invasive salmonellosis. 2003.

31. Barkume C, Date K, Saha SK, et al. Phase I of the Surveillance for Enteric Fever in Asia Project (SEAP): An Overview and Lessons Learned. J Infect Dis. 2018 Nov 10;218(suppl_4):S188-S194. doi: 10.1093/infdis/jiy522. PubMed PMID: 30304505; PubMed Central PMCID: PMCPMC6226726.

32. Msemo OA, Mbwana J, Mahende C, et al. Epidemiology and Antimicrobial Susceptibility of Salmonella enterica Bloodstream Isolates Among Febrile Children in a Rural District in Northeastern Tanzania: A Cross-sectional Study. Clin Infect Dis. 2019 Mar 7;68(Supplement_2):S177-s182. doi: 10.1093/cid/ciy1126. PubMed PMID: 30845323; PubMed Central PMCID: PMCPMC6405276. eng.

33. Lutterloh E, Likaka A, Sejvar J, et al. Multidrug-resistant typhoid fever with neurologic findings on the Malawi-Mozambique border. Clin Infect Dis. 2012 Apr;54(8):1100-6. doi: 10.1093/cid/cis012. PubMed PMID: 22357702.

34. Parry CM, Karunanayake $L$, Coulter JB, et al. Test for quinolone resistance in typhoid fever. BMJ. 2006 Jul 29;333(7561):260-1. doi: 10.1136/bmj.333.7561.260-b. PubMed PMID: 16873871; PubMed Central PMCID: PMCPMC1523447.

35. Bhutta ZA. Current concepts in the diagnosis and treatment of typhoid fever. BMJ. 2006 Jul 8;333(7558):78-82. doi: 10.1136/bmj.333.7558.78. PubMed PMID: 16825230; PubMed Central PMCID: PMCPMC1489205.

36. Britto $C D$, Wong VK, Dougan $G$, et al. A systematic review of antimicrobial resistance in Salmonella enterica serovar Typhi, the etiological agent of typhoid. PLoS Negl Trop Dis. 2018 Oct;12(10):e0006779. doi: 10.1371/journal.pntd.0006779. PubMed PMID: 30307935; PubMed Central PMCID: PMCPMC6198998 following competing interests. AJP has previously conducted studies on behalf of Oxford University funded by vaccine manufacturers, but currently does not undertake industry funded clinical trials. AJP chairs the UK Department of Health's (DH) Joint Committee on Vaccination and Immunisation (JCVI) and is a member of the World Health Organisation Strategic Group of Experts (SAGE); the views expressed in this manuscript do not necessarily reflect the views of JCVI, DH or SAGE. The other authors have no conflicts of interest.

37. Mutai WC, Muigai AWT, Waiyaki P, et al. Multi-drug resistant Salmonella enterica serovar Typhi isolates with reduced susceptibility to ciprofloxacin in Kenya. BMC Microbiol. 2018 Nov 14;18(1):187. doi: 10.1186/s12866-018-1332-3. PubMed PMID: 30428828; PubMed Central PMCID: PMCPMC6236932.

38. Thompson CN, Karkey A, Dongol S, et al. Treatment Response in Enteric Fever in an Era of Increasing Antimicrobial Resistance: An Individual Patient Data Analysis of 2092 Participants Enrolled into 4 Randomized, Controlled Trials in Nepal. Clin Infect 
Dis. 2017 Jun 1;64(11):1522-1531. doi: 10.1093/cid/cix185. PubMed PMID: 28329181; PubMed Central PMCID: PMCPMC5434338. eng.

39. Brown JC, Shanahan PM, Jesudason MV, et al. Mutations responsible for reduced susceptibility to 4-quinolones in clinical isolates of multi-resistant Salmonella typhi in India. J Antimicrob Chemother. 1996 May;37(5):891-900. doi: 10.1093/jac/37.5.891. PubMed PMID: 8737139.

40. Das JK, Hasan R, Zafar A, et al. Trends, Associations, and Antimicrobial Resistance of Salmonella Typhi and Paratyphi in Pakistan. Am J Trop Med Hyg. 2018 Sep;99(3_Suppl):48-54. doi: 10.4269/ajtmh.18-0145. PubMed PMID: 30047366; PubMed Central PMCID: PMCPMC6128361.

41. Rahman BA, Wasfy MO, Maksoud MA, et al. Multi-drug resistance and reduced susceptibility to ciprofloxacin among Salmonella enterica serovar Typhi isolates from the Middle East and Central Asia. New Microbes New Infect. 2014;2(4):88-92. doi: 10.1002/nmi2.46. PubMed PMID: 25356352; eng.

42. Arjyal A, Basnyat B, Nhan HT, et al. Gatifloxacin versus ceftriaxone for uncomplicated enteric fever in Nepal: an open-label, two-centre, randomised controlled trial. Lancet Infect Dis. 2016 May;16(5):535-545. doi: 10.1016/S1473-3099(15)00530-7. PubMed PMID: 26809813; PubMed Central PMCID: PMCPMC4835582.

43. Pham Thanh D, Karkey A, Dongol S, et al. A novel ciprofloxacin-resistant subclade of H58 Salmonella Typhi is associated with fluoroquinolone treatment failure. Elife. 2016 Mar 11;5:e14003. doi: 10.7554/eLife.14003. PubMed PMID: 26974227; PubMed Central PMCID: PMCPMC4805543. eng.

44. Wong VK, Baker S, Pickard DJ, et al. Phylogeographical analysis of the dominant multidrug-resistant $\mathrm{H} 58$ clade of Salmonella Typhi identifies inter- and intracontinental transmission events. Nat Genet. 2015 Jun;47(6):632-9. doi: 10.1038/ng.3281. PubMed PMID: 25961941; PubMed Central PMCID: PMCPMC4921243.

45. Tacconelli E, Carrara E, Savoldi A, et al. Discovery, research, and development of new antibiotics: the WHO priority list of antibiotic-resistant bacteria and tuberculosis. Lancet Infect Dis. 2018 Mar;18(3):318-327. doi: 10.1016/S1473-3099(17)30753-3. PubMed PMID: 29276051.

46. Cooke FJ, Wain J. The emergence of antibiotic resistance in typhoid fever. Travel Med Infect Dis. 2004 May;2(2):67-74. doi: 10.1016/j.tmaid.2004.04.005. PubMed PMID: 17291961.

47. Ahsan S, Rahman S. Azithromycin Resistance in Clinical Isolates of Salmonella enterica Serovars Typhi and Paratyphi in Bangladesh. Microb Drug Resist. 2019 Jan/Feb;25(1):8-13. doi: 10.1089/mdr.2018.0109. PubMed PMID: 30016183.

48. Vlieghe ER, Phe T, De Smet B, et al. Azithromycin and ciprofloxacin resistance in Salmonella bloodstream infections in Cambodian adults. PLoS Negl Trop Dis. 2012;6(12):e1933. doi: 10.1371/journal.pntd.0001933. PubMed PMID: 23272255; PubMed Central PMCID: PMCPMC3521708.

49. Sultan S, Zaheer HA, Waheed U, et al. Internal quality control of blood products: An experience from a tertiary care hospital blood bank from Southern Pakistan. J Lab Physicians. 2018 Jan-Mar;10(1):64-67. doi: 10.4103/JLP.JLP_97_17. PubMed PMID: 29403208 ; PubMed Central PMCID: PMCPMC5784297. 
50. Capoor MR, Nair D, Posti J, et al. Minimum inhibitory concentration of carbapenems and tigecycline against Salmonella spp. Journal of medical microbiology. 2009 Mar;58(Pt 3):337-41. doi: 10.1099/jmm.0.47853-0. PubMed PMID: 19208884; eng.

51. Gotuzzo E, Echevarria J, Carrillo C, et al. Randomized comparison of aztreonam and chloramphenicol in treatment of typhoid fever. Antimicrob Agents Chemother. 1994 Mar;38(3):558-62. doi: 10.1128/aac.38.3.558. PubMed PMID: 8203854; PubMed Central PMCID: PMCPMC284497. eng.

52. Parry CM, Ho VA, Phuong le T, et al. Randomized controlled comparison of ofloxacin, azithromycin, and an ofloxacin-azithromycin combination for treatment of multidrug-resistant and nalidixic acid-resistant typhoid fever. Antimicrob Agents Chemother. 2007 Mar;51(3):819-25. doi: 10.1128/aac.00447-06. PubMed PMID: 17145784; PubMed Central PMCID: PMCPMC1803150. eng.

53. Zmora N, Shrestha S, Neuberger A, et al. Open label comparative trial of mono versus dual antibiotic therapy for Typhoid Fever in adults. PLoS Negl Trop Dis. 2018 Apr;12(4):e0006380. doi: 10.1371/journal.pntd.0006380. PubMed PMID: 29684022; PubMed Central PMCID: PMCPMC5912710. eng.

54. Ivanoff $B$, Levine MM. Typhoid fever: continuing challenges from a resilient bacterial foe. Bulletin de I'Institut Pasteur. 1997 1997/07/01/;95(3):129-142. doi: https://doi.org/10.1016/S0020-2452(97)81367-X.

55. Woodward WE. Volunteer studies of typhoid fever and vaccines. Trans R Soc Trop Med Hyg. 1980;74(5):553-6. doi: 10.1016/0035-9203(80)90133-9. PubMed PMID: 7210105.

56. Woodward TE, Woodward WE. A new oral vaccine against typhoid fever. J Infect Dis. 1982 Mar;145(3):289-91. doi: 10.1093/infdis/145.3.289. PubMed PMID: 7037981.

57. The history of typhoid and of the development of anti-typhoid vaccine [Internet]. 1946.

58. Flower D. Vaccines: How They Work. Bioinformatics for Vaccinology.

59. Levine MM, Ferreccio C, Black RE, et al. Progress in vaccines against typhoid fever. Rev Infect Dis. 1989 May-Jun;11 Suppl 3:S552-67. doi: 10.1093/clinids/11.supplement_3.s552. PubMed PMID: 2669099.

60. Marathe SA, Lahiri A, Negi VD, et al. Typhoid fever \& vaccine development: a partially answered question. The Indian journal of medical research. 2012;135(2):161-169. PubMed PMID: 22446857; eng.

61. Germanier R, Fuer E. Isolation and characterization of Gal E mutant Ty 21a of Salmonella typhi: a candidate strain for a live, oral typhoid vaccine. J Infect Dis. 1975 May;131(5):553-8. doi: 10.1093/infdis/131.5.553. PubMed PMID: 1092768; eng.

62. Pasetti MF, Simon JK, Sztein MB, et al. Immunology of gut mucosal vaccines. Immunol Rev. 2011 Jan;239(1):125-48. doi: 10.1111/j.1600-065X.2010.00970.x. PubMed PMID: 21198669; PubMed Central PMCID: PMCPMC3298192. eng.

63. Amicizia D, Arata L, Zangrillo F, et al. Overview of the impact of Typhoid and Paratyphoid fever. Utility of Ty21a vaccine (Vivotif(R)). J Prev Med Hyg. 2017 Mar;58(1):E1-e8. PubMed PMID: 28515625; PubMed Central PMCID: PMCPMC5432773. eng.

64. Gilman RH, Hornick RB, Woodard WE, et al. Evaluation of a UDP-glucose-4epimeraseless mutant of Salmonella typhi as a liver oral vaccine. J Infect Dis. 1977 Dec;136(6):717-23. doi: 10.1093/infdis/136.6.717. PubMed PMID: 925379; eng. 
65. Levine MM, Ferreccio C, Black RE, et al. Large-scale field trial of Ty21a live oral typhoid vaccine in enteric-coated capsule formulation. Lancet. 1987 May 9;1(8541):1049-52. doi: 10.1016/s0140-6736(87)90480-6. PubMed PMID: 2883393; eng.

66. Simanjuntak $\mathrm{CH}$, Paleologo FP, Punjabi $\mathrm{NH}$, et al. Oral immunisation against typhoid fever in Indonesia with Ty21a vaccine. Lancet. 1991 Oct 26;338(8774):1055-9. doi: 10.1016/0140-6736(91)91910-m. PubMed PMID: 1681365; eng.

67. Milligan R, Paul M, Richardson $M$, et al. Vaccines for preventing typhoid fever. Cochrane Database of Systematic Reviews. 2018 (5). doi: 10.1002/14651858.CD001261.pub4. PubMed PMID: CD001261.

**68. Hu X, Chen Z, Xiong K, et al. Vi capsular polysaccharide: Synthesis, virulence, and application. Crit Rev Microbiol. 2017 Aug;43(4):440-452. doi: 10.1080/1040841x.2016.1249335. PubMed PMID: 27869515; eng. ** Cochrane review of evidence supporting use of currently available typhoid vaccines**

69. Garmory HS, Brown KA, Titball RW. Salmonella vaccines for use in humans: present and future perspectives. FEMS Microbiol Rev. 2002 Nov;26(4):339-53. doi: 10.1111/j.1574-6976.2002.tb00619.x. PubMed PMID: 12413664; eng.

70. Khan MI, Ochiai RL, Clemens JD. Population impact of Vi capsular polysaccharide vaccine. Expert Rev Vaccines. 2010 May;9(5):485-96. doi: 10.1586/erv.10.43. PubMed PMID: 20450323; eng.

71. Scobie HM, Nilles E, Kama M, et al. Impact of a targeted typhoid vaccination campaign following cyclone Tomas, Republic of Fiji, 2010. Am J Trop Med Hyg. 2014 Jun;90(6):1031-8. doi: 10.4269/ajtmh.13-0728. PubMed PMID: 24710618; PubMed Central PMCID: PMCPMC4047725. eng.

72. Klugman KP, Gilbertson IT, Koornhof HJ, et al. Protective activity of Vi capsular polysaccharide vaccine against typhoid fever. Lancet. 1987 Nov 21;2(8569):1165-9. doi: 10.1016/s0140-6736(87)91316-x. PubMed PMID: 2890805; eng.

73. Yang HH, Wu CG, Xie GZ, et al. Efficacy trial of Vi polysaccharide vaccine against typhoid fever in south-western China. Bull World Health Organ. 2001;79(7):625-31. PubMed PMID: 11477965; PubMed Central PMCID: PMCPMC2566475. eng.

74. Acharya IL, Lowe CU, Thapa R, et al. Prevention of typhoid fever in Nepal with the Vi capsular polysaccharide of Salmonella typhi. A preliminary report. N Engl J Med. 1987 Oct 29;317(18):1101-4. doi: 10.1056/nejm198710293171801. PubMed PMID: 3657877; eng.

75. Sur D, Ochiai RL, Bhattacharya SK, et al. A Cluster-Randomized Effectiveness Trial of Vi Typhoid Vaccine in India. New England Journal of Medicine. 2009;361(4):335-344. doi: 10.1056/NEJMoa0807521. PubMed PMID: 19625715.

76. Khan MI, Soofi SB, Ochiai RL, et al. Effectiveness of Vi capsular polysaccharide typhoid vaccine among children: a cluster randomized trial in Karachi, Pakistan. Vaccine. 2012 Aug 3;30(36):5389-95. doi: 10.1016/j.vaccine.2012.06.015. PubMed PMID: 22721899; eng.

77. Hessel L, Debois H, Fletcher M, et al. Experience With Salmonella typhi Vi Capsular Polysaccharide Vaccine [journal article]. European Journal of Clinical Microbiology and Infectious Diseases. 1999 October 01;18(9):609-620. doi: $10.1007 / \mathrm{s} 100960050361$.

78. Klein Klouwenberg P, Bont L. Neonatal and infantile immune responses to encapsulated bacteria and conjugate vaccines. Clin Dev Immunol. 
2008;2008:628963. doi: 10.1155/2008/628963. PubMed PMID: 18825269; PubMed Central PMCID: PMCPMC2553187. eng.

79. Weintraub A. Immunology of bacterial polysaccharide antigens. Carbohydr Res. 2003 Nov 14;338(23):2539-47. doi: 10.1016/j.carres.2003.07.008. PubMed PMID: 14670715; eng.

80. Michel R, Garnotel E, Spiegel A, et al. Outbreak of typhoid fever in vaccinated members of the French Armed Forces in the Ivory Coast. Eur J Epidemiol. 2005;20(7):635-42. doi: 10.1007/s10654-005-7454-6. PubMed PMID: 16119438; eng.

81. Keitel WA, Bond NL, Zahradnik JM, et al. Clinical and serological responses following primary and booster immunization with Salmonella typhi Vi capsular polysaccharide vaccines. Vaccine. 1994 1994/01/01/;12(3):195-199. doi: https://doi.org/10.1016/0264-410X(94)90194-5.

82. Ni Y, Springer MJ, Guo J, et al. Development of a synthetic Vi polysaccharide vaccine for typhoid fever. Vaccine. 2017;35(51):7121-7126. doi: 10.1016/j.vaccine.2017.10.081. PubMed PMID: 29150208; eng.

83. Szu SC, Stone AL, Robbins JD, et al. Vi capsular polysaccharide-protein conjugates for prevention of typhoid fever. Preparation, characterization, and immunogenicity in laboratory animals. J Exp Med. 1987 Nov 1;166(5):1510-24. doi: 10.1084/jem.166.5.1510. PubMed PMID: 3681191; PubMed Central PMCID: PMCPMC2189650. eng.

84. Szu SC, Taylor DN, Trofa AC, et al. Laboratory and preliminary clinical characterization of Vi capsular polysaccharide-protein conjugate vaccines. Infect Immun. 1994 Oct;62(10):4440-4. PubMed PMID: 7927707; PubMed Central PMCID: PMCPMC303128. eng.

85. Kossaczka Z, Lin FY, Ho VA, et al. Safety and immunogenicity of Vi conjugate vaccines for typhoid fever in adults, teenagers, and 2- to 4-year-old children in Vietnam. Infect Immun. 1999 Nov;67(11):5806-10. PubMed PMID: 10531232; PubMed Central PMCID: PMCPMC96958. eng.

86. Canh DG, Lin FY, Thiem VD, et al. Effect of dosage on immunogenicity of a Vi conjugate vaccine injected twice into 2- to 5-year-old Vietnamese children. Infect Immun. 2004 Nov;72(11):6586-8. doi: 10.1128/iai.72.11.6586-6588.2004. PubMed PMID: 15501790; PubMed Central PMCID: PMCPMC523060. eng.

87. Lin FY, Ho VA, Khiem HB, et al. The efficacy of a Salmonella typhi Vi conjugate vaccine in two-to-five-year-old children. N Engl J Med. 2001 Apr 26;344(17):1263-9. doi: 10.1056/nejm200104263441701. PubMed PMID: 11320385; eng.

88. Thiem VD, Lin FY, Canh DG, et al. The Vi conjugate typhoid vaccine is safe, elicits protective levels of IgG anti-Vi, and is compatible with routine infant vaccines. Clin Vaccine Immunol. 2011 May;18(5):730-5. doi: 10.1128/cvi.00532-10. PubMed PMID: 21411598; PubMed Central PMCID: PMCPMC3122535. eng.

89. Shakya M, Colin-Jones R, Theiss-Nyland K, et al. Phase 3 Efficacy Analysis of a Typhoid Conjugate Vaccine Trial in Nepal. 2019;381(23):2209-2218. doi: 10.1056/NEJMoa1905047. PubMed PMID: 31800986.

90. Mohan VK, Varanasi V, Singh A, et al. Safety and immunogenicity of a Vi polysaccharide-tetanus toxoid conjugate vaccine (Typbar-TCV) in healthy infants, children, and adults in typhoid endemic areas: a multicenter, 2-cohort, open-label, double-blind, randomized controlled phase 3 study. Clin Infect Dis. 2015 Aug 1;61(3):393-402. doi: 10.1093/cid/civ295. PubMed PMID: 25870324; eng. 
91. Mitra M, Shah N, Ghosh A, et al. Efficacy and safety of vi-tetanus toxoid conjugated typhoid vaccine (PedaTyph) in Indian children: School based cluster randomized study. Hum Vaccin Immunother. 2016 Apr 2;12(4):939-45. doi: 10.1080/21645515.2015.1117715. PubMed PMID: 26901576; PubMed Central PMCID: PMCPMC4962969. eng.

92. Background Paper to SAGE on Typhoid Vaccine Policy Recommendations [Internet]. SAGE Meeting October 2017; 2017

93. The L. A new vaccine for typhoid control. The Lancet. 2018 2018/01/13/;391(10116):96. doi: https://doi.org/10.1016/S0140-6736(18)30050-3.

*94. Sahastrabuddhe S, Saluja T. Overview of the Typhoid Conjugate Vaccine Pipeline: Current Status and Future Plans. Clinical Infectious Diseases.

2019;68(Supplement_1):S22-S26. doi: 10.1093/cid/ciy884. * A novel concept using serological evidence of typhoid infection to estimate incidence of typhoid and efficacy of a TCV*

**95. Voysey M, Pollard AJ. Seroefficacy of Vi Polysaccharide-Tetanus Toxoid Typhoid Conjugate Vaccine (Typbar TCV). Clin Infect Dis. 2018 Jun 18;67(1):18-24. doi: 10.1093/cid/cix1145. PubMed PMID: 29351594; eng. **A randomized control trial using a human challenge model to estimate the efficacy of a typhoid conjugate vaccine. Human challenge models offer an estimate of efficacy without the cost of a large-scale field trial**

96. Darton TC, Blohmke CJ, Moorthy VS, et al. Design, recruitment, and microbiological considerations in human challenge studies. Lancet Infect Dis. 2015 Jul;15(7):840-51. doi: 10.1016/s1473-3099(15)00068-7. PubMed PMID: 26026195; eng.

97. Jin C, Gibani MM, Moore M, et al. Efficacy and immunogenicity of a Vi-tetanus toxoid conjugate vaccine in the prevention of typhoid fever using a controlled human infection model of Salmonella Typhi: a randomised controlled, phase $2 \mathrm{~b}$ trial. Lancet. 2017 Dec 2;390(10111):2472-2480. doi: 10.1016/s0140-6736(17)32149-9. PubMed PMID: 28965718; PubMed Central PMCID: PMCPMC5720597. eng.

98. Theiss-Nyland K, Qadri F, Colin-Jones R, et al. Assessing the Impact of a Vipolysaccharide Conjugate Vaccine in Preventing Typhoid Infection Among Bangladeshi Children: A Protocol for a Phase IIIb Trial. Clinical Infectious Diseases. 2019;68(Supplement_2):S74-S82. doi: 10.1093/cid/ciy1107.

99. Theiss-Nyland K, Shakya M, Colin-Jones R, et al. Assessing the Impact of a Vipolysaccharide Conjugate Vaccine in Preventing Typhoid Infections Among Nepalese Children: A Protocol for a Phase III, Randomized Control Trial. Clinical Infectious Diseases. 2019;68(Supplement_2):S67-S73. doi: 10.1093/cid/ciy1106.

100. Meiring JE, Laurens MB, Patel P, et al. Typhoid Vaccine Acceleration Consortium Malawi: A Phase III, Randomized, Double-blind, Controlled Trial of the Clinical Efficacy of Typhoid Conjugate Vaccine Among Children in Blantyre, Malawi. Clin Infect Dis. 2019 Mar 7;68(Supplement_2):S50-s58. doi: 10.1093/cid/ciy1103. PubMed PMID: 30845320; PubMed Central PMCID: PMCPMC6405268. eng.

101. Cook J, Jeuland $M$, Whittington $D$, et al. The cost-effectiveness of typhoid Vi vaccination programs: calculations for four urban sites in four Asian countries. Vaccine. 2008 Nov 25;26(50):6305-16. doi: 10.1016/j.vaccine.2008.09.040. PubMed PMID: 18835415. 
102. Bahl R, Sinha A, Poulos C, et al. Costs of illness due to typhoid fever in an Indian urban slum community: implications for vaccination policy. J Health Popul Nutr. 2004 Sep;22(3):304-10. PubMed PMID: 15609783; eng.

103. Luthra K, Watts E, Debellut F, et al. A Review of the Economic Evidence of Typhoid Fever and Typhoid Vaccines. Clin Infect Dis. 2019 Mar 7;68(Supplement_2):S83-S95. doi: 10.1093/cid/ciy1122. PubMed PMID: 30845334; PubMed Central PMCID: PMCPMC6405266.

104. Riewpaiboon A, Piatti M, Ley B, et al. Cost of illness due to typhoid Fever in pemba, zanzibar, East Africa. J Health Popul Nutr. 2014 Sep;32(3):377-85. PubMed PMID: 25395900; PubMed Central PMCID: PMCPMC4221443. eng.

105. Antillon M, Bilcke J, Paltiel AD, et al. Cost-effectiveness analysis of typhoid conjugate vaccines in five endemic low- and middle-income settings. Vaccine. $2017 \mathrm{Jun}$ 14;35(27):3506-3514. doi: 10.1016/j.vaccine.2017.05.001. PubMed PMID: 28527687; PubMed Central PMCID: PMCPMC5462484.

106. Bilcke J, Antillon M, Pieters Z, et al. Cost-effectiveness of routine and campaign use of typhoid Vi-conjugate vaccine in Gavi-eligible countries: a modelling study. Lancet Infect Dis. 2019 Jul;19(7):728-739. doi: 10.1016/s1473-3099(18)30804-1. PubMed PMID: 31130329; PubMed Central PMCID: PMCPMC6595249. eng.

107. Fiorino $F$, Ciabattini $A$, Rondini $S$, et al. Immunization with the conjugate vaccine $\mathrm{Vi-}$ $\operatorname{CRM}(1)(9)(7)$ against Salmonella typhi induces Vi-specific mucosal and systemic immune responses in mice. Vaccine. 2012 Sep 21;30(43):6111-4. doi: 10.1016/j.vaccine.2012.05.081. PubMed PMID: 22705173; eng.

108. Bhutta ZA, Capeding MR, Bavdekar A, et al. Immunogenicity and safety of the ViCRM197 conjugate vaccine against typhoid fever in adults, children, and infants in south and southeast Asia: results from two randomised, observer-blind, age deescalation, phase 2 trials. Lancet Infect Dis. 2014 Feb;14(2):119-29. doi: 10.1016/s1473-3099(13)70241-x. PubMed PMID: 24290843; eng.

109. Szu SC, Lin KF, Hunt S, et al. Phase I clinical trial of O-acetylated pectin conjugate, a plant polysaccharide based typhoid vaccine. Vaccine. 2014 May 7;32(22):2618-22. doi: 10.1016/j.vaccine.2014.03.023. PubMed PMID: 24657719; PubMed Central PMCID: PMCPMC4034380. eng.

110. Baker S, Sarwar Y, Aziz H, et al. Detection of Vi-negative Salmonella enterica serovar typhi in the peripheral blood of patients with typhoid fever in the Faisalabad region of Pakistan. J Clin Microbiol. 2005 Sep;43(9):4418-25. doi: 10.1128/jcm.43.9.44184425.2005. PubMed PMID: 16145086; PubMed Central PMCID: PMCPMC1234127. eng.

111. Wain J, House D, Zafar A, et al. Vi antigen expression in Salmonella enterica serovar Typhi clinical isolates from Pakistan. J Clin Microbiol. 2005 Mar;43(3):1158-65. doi: 10.1128/jcm.43.3.1158-1165.2005. PubMed PMID: 15750077; PubMed Central PMCID: PMCPMC1081282. eng.

112. Pulickal AS, Callaghan MJ, Kelly DF, et al. Prevalence and genetic analysis of phenotypically Vi- negative Salmonella typhi isolates in children from Kathmandu, Nepal. J Trop Pediatr. 2013 Aug;59(4):317-20. doi: 10.1093/tropej/fmt024. PubMed PMID: 23598894; eng.

113. Lyon CE, Sadigh KS, Carmolli MP, et al. In a randomized, double-blinded, placebocontrolled trial, the single oral dose typhoid vaccine, M01ZH09, is safe and immunogenic at doses up to $1.7 \times 10$ (10) colony-forming units. Vaccine. $2010 \mathrm{Apr}$ 
30;28(20):3602-8. doi: 10.1016/j.vaccine.2010.02.017. PubMed PMID: 20188175; eng.

114. Kirkpatrick BD, McKenzie R, O'Neill JP, et al. Evaluation of Salmonella enterica serovar Typhi (Ty2 aroC-ssaV-) M01ZH09, with a defined mutation in the Salmonella pathogenicity island 2, as a live, oral typhoid vaccine in human volunteers. Vaccine. 2006 Jan 12;24(2):116-23. doi: 10.1016/j.vaccine.2005.08.008. PubMed PMID: 16140433; eng.

115. Darton TC, Jones C, Blohmke CJ, et al. Using a Human Challenge Model of Infection to Measure Vaccine Efficacy: A Randomised, Controlled Trial Comparing the Typhoid Vaccines M01ZH09 with Placebo and Ty21a. PLoS NegI Trop Dis. 2016

Aug;10(8):e0004926. doi: 10.1371/journal.pntd.0004926. PubMed PMID: 27533046; PubMed Central PMCID: PMCPMC4988630. eng.

116. Salerno-Goncalves R, Galen JE, Levine MM, et al. Manipulation of Salmonella Typhi Gene Expression Impacts Innate Cell Responses in the Human Intestinal Mucosa. Front Immunol. 2018;9:2543. doi: 10.3389/fimmu.2018.02543. PubMed PMID: 30443257; PubMed Central PMCID: PMCPMC6221971. eng.

117. Wang JY, Noriega FR, Galen JE, et al. Constitutive expression of the Vi polysaccharide capsular antigen in attenuated Salmonella enterica serovar typhi oral vaccine strain CVD 909. Infect Immun. 2000 Aug;68(8):4647-52. doi: 10.1128/iai.68.8.46474652.2000. PubMed PMID: 10899868; PubMed Central PMCID: PMCPMC98400. eng.

118. Tacket CO, Pasetti MF, Sztein MB, et al. Immune responses to an oral typhoid vaccine strain that is modified to constitutively express $V i$ capsular polysaccharide. J Infect Dis. 2004 Aug 1;190(3):565-70. doi: 10.1086/421469. PubMed PMID: 15243933; eng.

119. Wahid R, Pasetti MF, Maciel M, Jr., et al. Oral priming with Salmonella Typhi vaccine strain CVD 909 followed by parenteral boost with the S. Typhi Vi capsular polysaccharide vaccine induces CD27+lgD-S. Typhi-specific IgA and IgG B memory cells in humans. Clin Immunol. 2011 Feb;138(2):187-200. doi: 10.1016/j.clim.2010.11.006. PubMed PMID: 21146460; PubMed Central PMCID: PMCPMC3035995. eng.

120. Grabenstein JD, Pittman PR, Greenwood JT, et al. Immunization to protect the US Armed Forces: heritage, current practice, and prospects. Epidemiol Rev. 2006;28:326. doi: 10.1093/epirev/mxj003. PubMed PMID: 16763072; eng.

121. Wahid R, Simon R, Zafar SJ, et al. Live oral typhoid vaccine Ty21a induces crossreactive humoral immune responses against Salmonella enterica serovar Paratyphi $A$ and S. Paratyphi B in humans. Clin Vaccine Immunol. 2012 Jun;19(6):825-34. doi: 10.1128/cvi.00058-12. PubMed PMID: 22492745; PubMed Central PMCID: PMCPMC3370435. eng.

122. Wahid R, Fresnay S, Levine MM, et al. Immunization with Ty21a live oral typhoid vaccine elicits crossreactive multifunctional CD8+ T-cell responses against Salmonella enterica serovar Typhi, S. Paratyphi A, and S. Paratyphi B in humans. Mucosal Immunol. 2015 Nov;8(6):1349-59. doi: 10.1038/mi.2015.24. PubMed PMID: 25872480; PubMed Central PMCID: PMCPMC4607552. eng.

123. Levine MM, Ferreccio C, Black RE, et al. Ty21a live oral typhoid vaccine and prevention of paratyphoid fever caused by Salmonella enterica Serovar Paratyphi B. Clin Infect Dis. 2007 Jul 15;45 Suppl 1:S24-8. doi: 10.1086/518141. PubMed PMID: 17582564; eng. 
124. McCullagh D, Dobinson HC, Darton T, et al. Understanding paratyphoid infection: study protocol for the development of a human model of Salmonella enterica serovar Paratyphi A challenge in healthy adult volunteers. BMJ Open. 2015 Jun 16;5(6):e007481. doi: 10.1136/bmjopen-2014-007481. PubMed PMID: 26082464; PubMed Central PMCID: PMCPMC4480031. eng.

125. Arndt MB, Mosites EM, Tian M, et al. Estimating the burden of paratyphoid a in Asia and Africa. PLoS Negl Trop Dis. 2014 Jun;8(6):e2925. doi:

10.1371/journal.pntd.0002925. PubMed PMID: 24901439; PubMed Central PMCID: PMCPMC4046978. eng.

126. Martin LB, Simon R, MacLennan CA, et al. Status of paratyphoid fever vaccine research and development. Vaccine. 2016 Jun 3;34(26):2900-2902. doi: 10.1016/j.vaccine.2016.03.106. PubMed PMID: 27083427; eng.

127. Micoli F, Rondini S, Gavini M, et al. O:2-CRM(197) conjugates against Salmonella Paratyphi A. PLoS One. 2012;7(11):e47039. doi: 10.1371/journal.pone.0047039. PubMed PMID: 23144798; PubMed Central PMCID: PMCPMC3492368. eng.

128. Konadu EY, Lin FY, Ho VA, et al. Phase 1 and phase 2 studies of Salmonella enterica serovar paratyphi A O-specific polysaccharide-tetanus toxoid conjugates in adults, teenagers, and 2- to 4-year-old children in Vietnam. Infect Immun. 2000 Mar;68(3):1529-34. doi: 10.1128/iai.68.3.1529-1534.2000. PubMed PMID: 10678970; PubMed Central PMCID: PMCPMC97311. eng.

129. Gat O, Galen JE, Tennant S, et al. Cell-associated flagella enhance the protection conferred by mucosally-administered attenuated Salmonella Paratyphi A vaccines. PLoS Negl Trop Dis. 2011 Nov;5(11):e1373. doi: 10.1371/journal.pntd.0001373. PubMed PMID: 22069504; PubMed Central PMCID: PMCPMC3206010. eng.

130. Higginson EE, Ramachandran G, Hazen TH, et al. Improving Our Understanding of Salmonella enterica Serovar Paratyphi B through the Engineering and Testing of a Live Attenuated Vaccine Strain. mSphere. 2018 Nov 28;3(6). doi: 10.1128/mSphere.00474-18. PubMed PMID: 30487152; PubMed Central PMCID: PMCPMC6262260. eng.

131. Ao TT, Feasey NA, Gordon MA, et al. Global burden of invasive nontyphoidal Salmonella disease, 2010(1). Emerg Infect Dis. 2015 Jun;21(6). doi: 10.3201/eid2106.140999. PubMed PMID: 25860298; PubMed Central PMCID: PMCPMC4451910. eng.

132. Uche IV, MacLennan CA, Saul A. A Systematic Review of the Incidence, Risk Factors and Case Fatality Rates of Invasive Nontyphoidal Salmonella (iNTS) Disease in Africa (1966 to 2014). PLoS neglected tropical diseases. 2017;11(1):e0005118-e0005118. doi: 10.1371/journal.pntd.0005118. PubMed PMID: 28056035; eng.

133. Feasey NA, Dougan G, Kingsley RA, et al. Invasive non-typhoidal salmonella disease: an emerging and neglected tropical disease in Africa. Lancet (London, England). 2012;379(9835):2489-2499. doi: 10.1016/S0140-6736(11)61752-2. PubMed PMID: 22587967; eng.

134. Gordon MA, Banda HT, Gondwe M, et al. Non-typhoidal salmonella bacteraemia among HIV-infected Malawian adults: high mortality and frequent recrudescence. AIDS (London, England). 2002 Aug 16;16(12):1633-41. doi: 10.1097/00002030200208160-00009. PubMed PMID: 12172085; eng. 
135. Tennant SM, MacLennan CA, Simon R, et al. Nontyphoidal salmonella disease: Current status of vaccine research and development. Vaccine. 2016 2016/06/03/;34(26):2907-2910. doi: https://doi.org/10.1016/j.vaccine.2016.03.072.

136. Zhao X, Dai Q, Jia R, et al. Two Novel Salmonella Bivalent Vaccines Confer Dual Protection against Two Salmonella Serovars in Mice. Front Cell Infect Microbiol. 2017;7:391-391. doi: 10.3389/fcimb.2017.00391. PubMed PMID: 28929089; eng.

137. Martin LB. Vaccines for typhoid fever and other salmonelloses. Curr Opin Infect Dis. 2012 Oct;25(5):489-99. doi: 10.1097/QCO.0b013e328356ffeb. PubMed PMID: 22825288; eng.

\begin{tabular}{|c|c|c|c|c|c|}
\hline Year & Study & Region & $\begin{array}{l}\text { Cases, millions } \\
\text { (95\% Cl or UI) }\end{array}$ & $\begin{array}{c}\text { Incidence per } \\
100,000 \\
(95 \% \mathrm{Cl} \text { or UI) } \\
\text { adjusted }\end{array}$ & $\begin{array}{c}\text { Deaths, } \\
\text { thousands } \\
\text { (95\% Cl or UI) } \\
\text { adjusted }\end{array}$ \\
\hline 1990 & $\begin{array}{l}\text { Stanaway, } \\
2019\end{array}$ & Global & $\begin{array}{c}25.9 \\
(22.0-22.9)\end{array}$ & $\begin{array}{c}439.2 \\
(376.7-507.7)\end{array}$ & $\begin{array}{c}230.5 \\
(131.2-372.6)\end{array}$ \\
\hline 2000 & Crump, 2004 & Global & 21 & 355 & 216 \\
\hline 2010 & $\begin{array}{l}\text { Mogasale, } \\
2014\end{array}$ & LMICs & $\begin{array}{c}11.9 \\
(0.9-14.7)\end{array}$ & 214 & $\begin{array}{c}129 \\
(75-208)\end{array}$ \\
\hline 2010 & Buckle, 2012 & Global & $\begin{array}{c}26.9 \\
(9.1-17.8)\end{array}$ & - & - \\
\hline 2017 & $\begin{array}{l}\text { Stanaway, } \\
2019\end{array}$ & Global & $\begin{array}{c}14.3 \\
(12.5-16.3)\end{array}$ & $\begin{array}{c}197.8 \\
(172.0-226.2)\end{array}$ & $\begin{array}{c}135.9 \\
(76.9-218.9)\end{array}$ \\
\hline $\begin{array}{l}\text { Per year } \\
(1980- \\
2014)\end{array}$ & Antillon, 2017 & 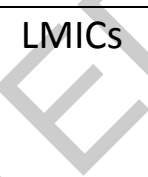 & $\begin{array}{c}17.8 \\
(6.9-48.4)\end{array}$ & $\begin{array}{c}293 \\
(111-794)\end{array}$ & - \\
\hline
\end{tabular}

Table 1. Global estimates of typhoid fever incidence and deaths

LMICs (Low and Middle Income Countries), $\mathrm{Cl}$ (Confidence Interval), UI (Uncertainty Interval) 


\begin{tabular}{|c|c|c|c|c|c|}
\hline Vaccine & $\begin{array}{l}\text { Route of } \\
\text { Administration }\end{array}$ & $\begin{array}{l}\text { Number of } \\
\text { Doses in } \\
\text { Primary } \\
\text { Schedule }\end{array}$ & $\begin{array}{l}\text { Currently } \\
\text { Recommended } \\
\text { for Use by } \\
\text { WHO }[3,4]\end{array}$ & $\begin{array}{l}\text { Recommended } \\
\text { Age Group for } \\
\text { Vaccination }\end{array}$ & $\begin{array}{l}\text { Recommended } \\
\text { Repeat } \\
\text { Vaccination } \\
\text { Interval }\end{array}$ \\
\hline $\begin{array}{l}\text { Inactivated } \\
\text { whole cell } \\
\text { vaccine }\end{array}$ & $\begin{array}{l}\text { Parenteral, } \\
\text { subcutaneous }\end{array}$ & $\begin{array}{l}2 \text { doses } \\
\text { given } 4 \\
\text { weeks apart }\end{array}$ & No & $\begin{array}{l}\text { Over } 2 \text { years of } \\
\text { age }\end{array}$ & Every 3 years \\
\hline Ty21a & $\begin{array}{l}\text { Oral, enteric } \\
\text { coated capsule } \\
\text { (liquid } \\
\text { formulation } \\
\text { previously } \\
\text { available) }\end{array}$ & $\begin{array}{l}3 \text { doses each } \\
\text { given } 2 \text { days } \\
\text { apart ( } 4 \\
\text { doses in } \\
\text { USA/Canada) }\end{array}$ & Yes & $\begin{array}{l}\text { Over } 6 \text { years of } \\
\text { age }\end{array}$ & $\begin{array}{l}\text { Every 3-7 years } \\
\text { if living in } \\
\text { endemic areas. } \\
\text { 1-7 years for } \\
\text { travelers to } \\
\text { endemic areas }\end{array}$ \\
\hline $\begin{array}{l}\text { Vi } \\
\text { polysaccharide }\end{array}$ & $\begin{array}{l}\text { Parenteral, } \\
\text { intramuscular } \\
\text { or } \\
\text { subcutaneous }\end{array}$ & 1 dose & Yes & $\begin{array}{l}\text { Over } 2 \text { years of } \\
\text { age }\end{array}$ & Every 3 years \\
\hline $\begin{array}{l}\text { Vi-TT - } \\
\text { PedaTyph }\end{array}$ & $\begin{array}{l}\text { Parenteral, } \\
\text { intramuscular }\end{array}$ & $\begin{array}{l}2 \text { doses, 4-8 } \\
\text { weeks } \\
\text { apart† }\end{array}$ & $\begin{array}{l}\text { No (licensed in } \\
\text { India) }\end{array}$ & $\begin{array}{l}\text { Over } 3 \text { months } \\
\text { of age* } \\
\text { (Safety data } \\
\text { available for } \\
\text { over } 6 \text { months) }\end{array}$ & $\begin{array}{l}\text { Every } 10 \\
\text { years* } \ddagger\end{array}$ \\
\hline $\begin{array}{l}\text { Vi-TT - Typbar } \\
\text { TCV }^{\mathrm{TM}}\end{array}$ & Parenteral & 1 dose & $\begin{array}{l}\text { Yes-WHO } \\
\text { preferred } \\
\text { vaccine }\end{array}$ & $\begin{array}{l}\text { From } 6 \text { months } \\
\text { of age to } 45 \\
\text { years of age }\end{array}$ & $\begin{array}{l}\text { Booster at } 3 \\
\text { years* } \\
\text { Protection may } \\
\text { persist for up } \\
\text { to } 5 \text { years§ }\end{array}$ \\
\hline
\end{tabular}

Table 2. Currently available typhoid vaccines

* Manufacturer recommendation [92]

¥ If 3-23 months of age, booster recommended at 24-30 months of age followed by repeat vaccinations every 10 years

$\S$ High titers of Anti-Vi IgG found in $84 \%$ of children 5 years post vaccination [90] 

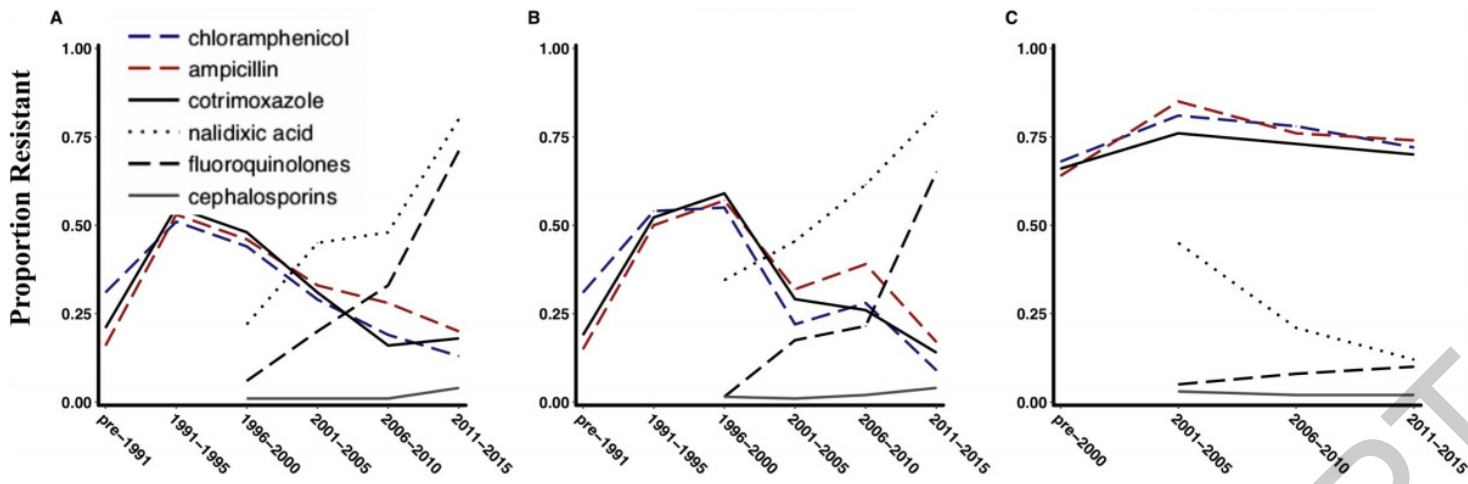

Time Period Intervals

Figure 1. Antimicrobial non-susceptible trends of S. Typhi over time. A) Global trends, B) Asian trends, C) African trends

Reproduced from [36] (Britto CD, Wong VK, Dougan G, et al. A systematic review of antimicrobial resistance in Salmonella enterica serovar Typhi, the etiological agent of typhoid. PLoS NegI Trop Dis. 2018

Oct;12(10):e0006779. https://doi.org/10.1371/journal.pntd.0006779.g002) under the terms of the Creative Commons Attribution License. 


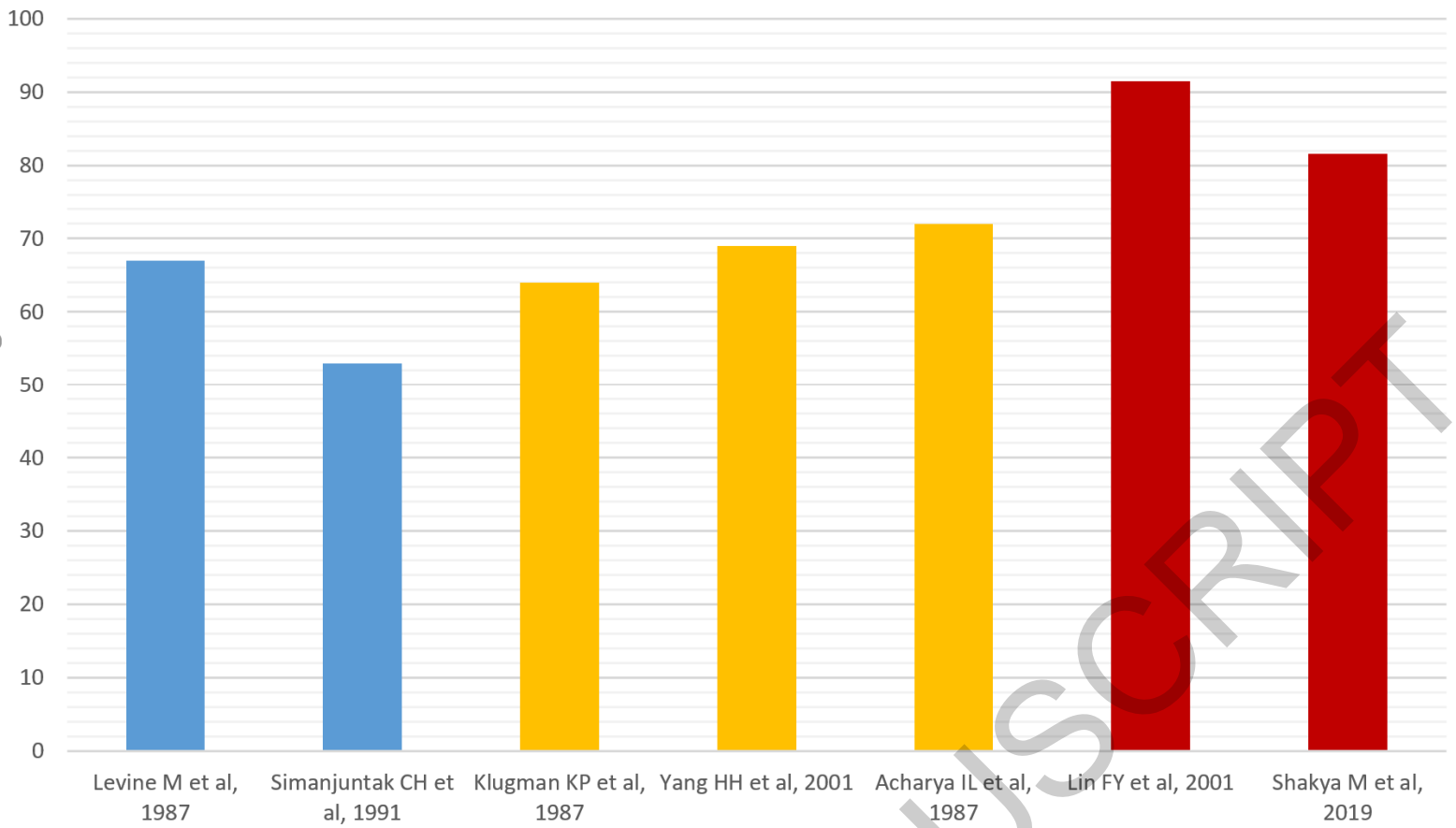

Figure 2. Percentage efficacy of current typhoid vaccines, results from large-scale field studies using culture positive typhoid fever as the outcome measure. 
Review: Vaccines for preventing typhoid tever

Comparison: 1 Ty21a vaccine (3 doses) versus control: etticac

lever at 2.5 to 3 years

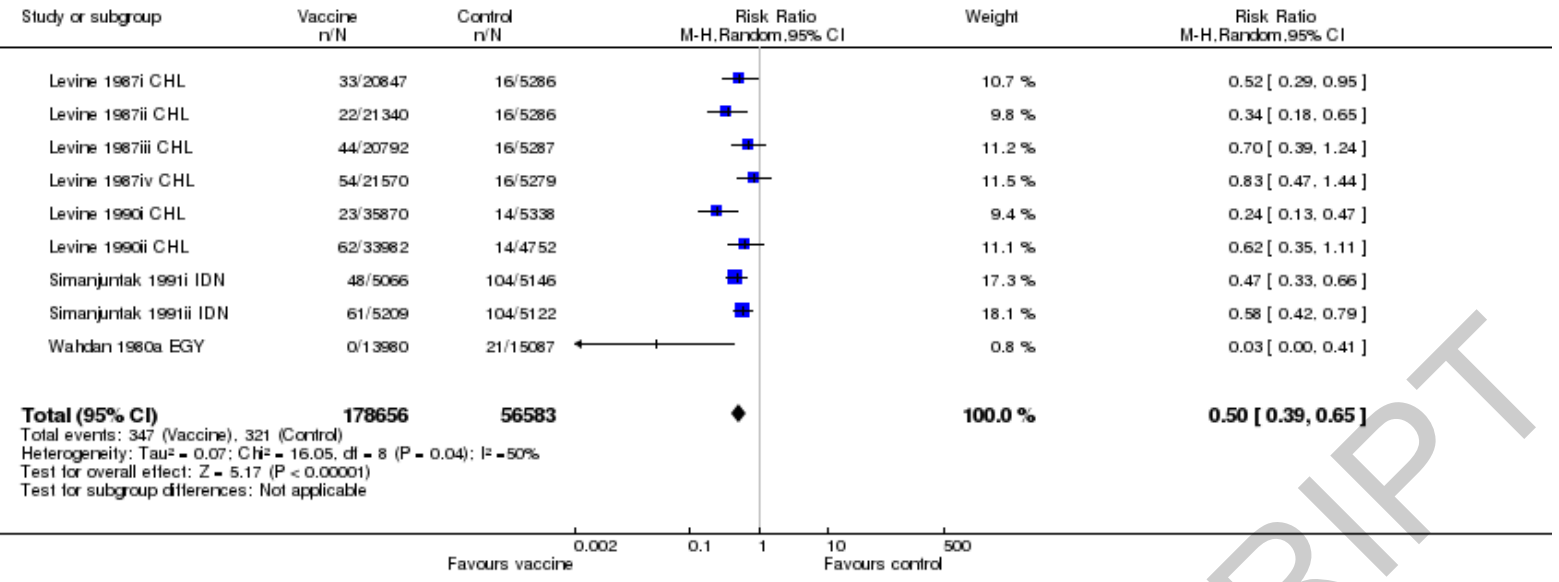

Figure 3. Ty21a vaccine (3 doses) versus control. Outcome: cumulative incidence of typhoid fever at 2.5 to 3 years. Figure reproduced with permission from [67] 
Review: Vaccines for preventing typhoid tever

Comparison: 5 Vi polysaccharide vaccine (1 dose) versus control: etlicacy Outcome: 1 Incidence of typhoid tever

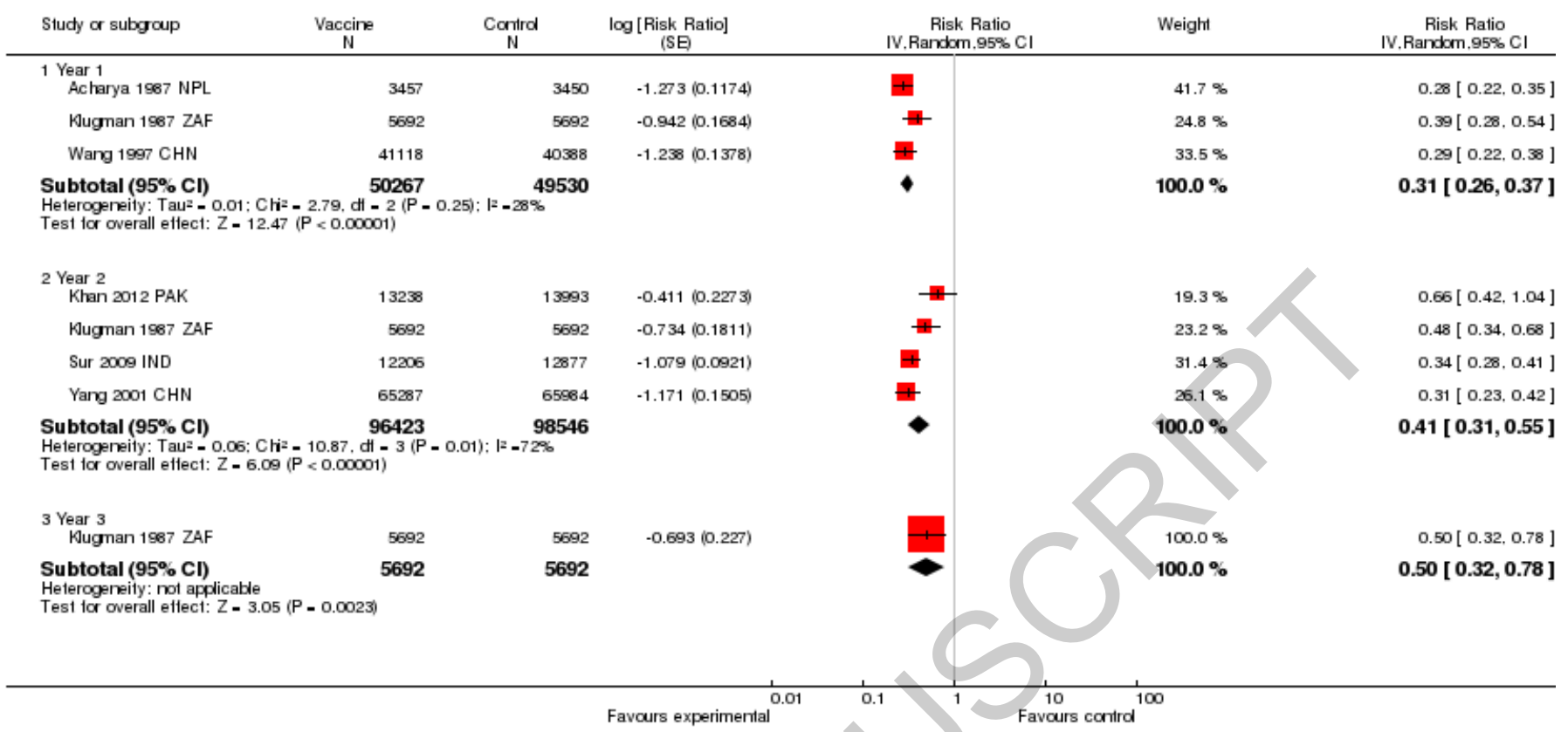

Figure 4. Vi polysaccharide vaccine (1 dose) versus control. Outcome: incidence of typhoid fever. Figure reproduced with permission from [67] 
Review: Vaccines tor preventing typhoid tever

Comparison: 7 Vi-rEPA (2 doses) versus control: etlicac

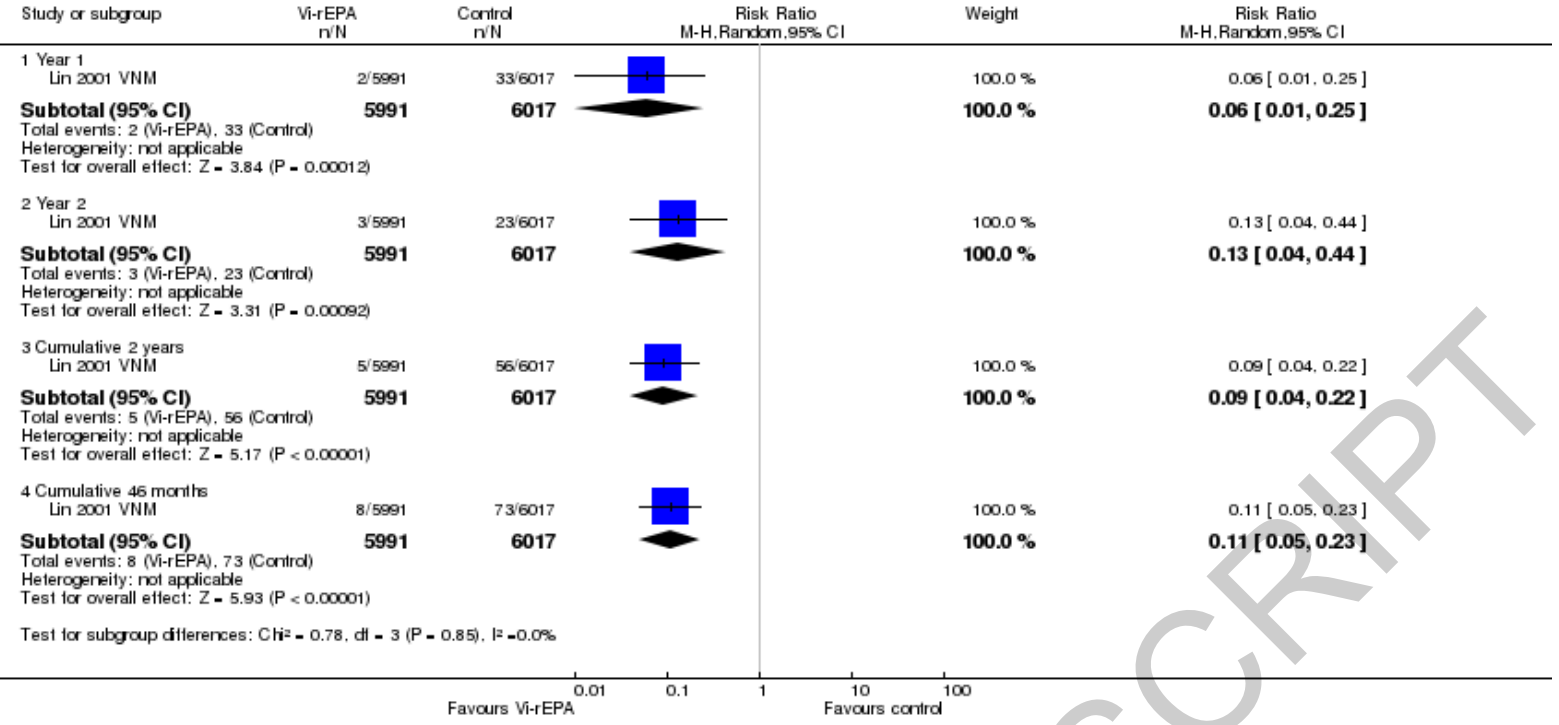

Figure 5. Vi-rEPA (2 doses) versus control. Outcome: incidence of typhoid fever. Figure reproduced with permission from [67] 
Review: Vaccines for preventing typhoid tever

Comparison: 9 Vi-IT vaccine Peda Typh (2 doses) versus control: etficac

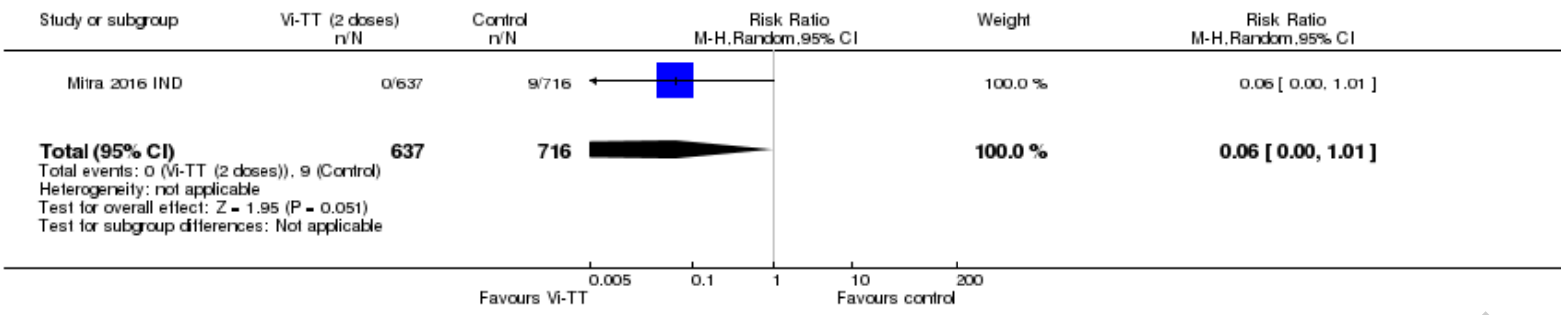

Figure 6. Vi-TT vaccine PedaTyph (2 doses) versus control. Outcome: incidence of typhoid fever, Year 1. Figure reproduced with permission from [67] 